\title{
Chapter 14 \\ Recent Development and Application of Seismic Isolation and Energy Dissipation and Conditions for Their Correct Use
}

\author{
Alessandro Martelli, Paolo Clemente, Alessandro De Stefano, \\ Massimo Forni, and Antonello Salvatori
}

\begin{abstract}
More than 23,000 structures, located in over 30 countries, have been so far protected by passive anti-seismic (AS) systems, mainly by the seismic isolation (SI) and energy dissipation (ED) ones. The use of such systems is going on increasing everywhere, although its extent is strongly influenced by earthquake lessons and the features of the design rules used. As to the latter, SI is considered as an additional safety measure (with consequent significant additional construction costs) in some countries (Japan, USA, etc.), while, in others (including Italy), the codes allow to partly take into account the reduction of the seismic forces acting on the superstructure that is induced by SI. Applications of the AS systems have been made to both new and existing civil and industrial structures of all kinds. The latter include some high risk (HR) plants (nuclear reactors and chemical installations). The applications in a civil context already include not only strategic and
\end{abstract}

\footnotetext{
A. Martelli $(\bowtie)$

ENEA, Via Venezia 34, San Lazzaro di Savena (Bologna) 40068, Italy

e-mail: marteisso1@gmail.com

P. Clemente

Laboratory on Prevention and Mitigation of Natural Risks, Casaccia Research Centre, ENEA, Via Anguillarese 301, 00123, Santa Maria di Galeria (Roma), Italy

e-mail: paolo.clemente@enea.it
}

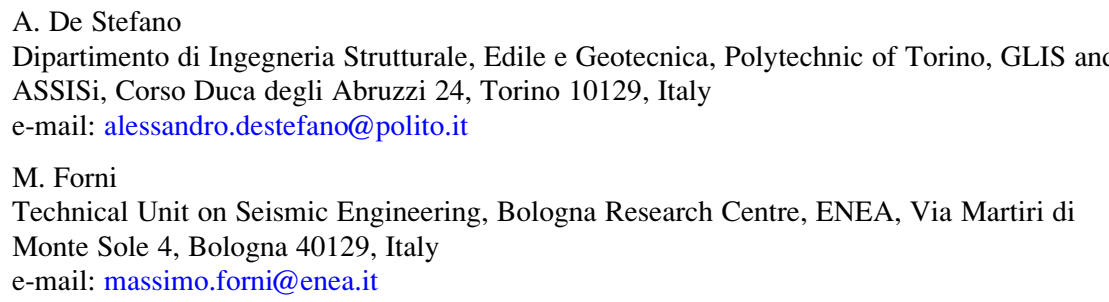

\section{A. Salvatori}

Dipartimento di Ingegneria Civile, Edile - Architettura e Ambientale, GLIS and ASSISi, University of L'Aquila, Via Campo di Pile, Zona Industriale di Pile, L'Aquila 67100, Italy e-mail: antonello.salvatori@alice.it 
public structures, but also residential buildings and even many small private houses. In Italy, the use of the AS systems has become more and more popular especially after the 2009 Abruzzo earthquake (nowadays more than 400 Italian buildings are seismically isolated). Based on the information provided by the authors at the ASSISi 13th World Conference, held in Sendai (Japan) in September 2013, and on more recent data, the paper summarizes the state-of-the-art of the development and application of the AS systems and devices at worldwide level, by devoting particular attention to SI of buildings in Italy, in the context of recent seismic events. Moreover, it outlines the benefits of the aforesaid systems for ensuring the indispensable absolute integrity of strategic and public structures, as, primarily, schools, hospitals and HR plants, but also (for an adequate protection of cultural heritage) museums. Finally, based on Italian experience, it provides some remarks on costs of SI, stresses the conditions for the correct use of this technique and mentions some recent initiatives of the Italian Parliament to ensure such a correct use and to widely extend such an use to the HR chemical plants too (for which only very few applications already exist in Italy).

\subsection{Introduction}

On September 24-26, 2013, the 13th event of the Anti-Seismic Systems International Society (ASSISi), namely the 13th World Conference on Seismic Isolation, Energy Dissipation and Active Vibrations Control of Structures \& JSSI 20th Anniversary International Symposium, took place in Sendai (Japan). This conference (JSSI 2013) was organized jointly with the Japan Society of Seismic Isolation (JSSI) and with the collaboration of the Italian association GLIS ("GLIS - Isolamento ed altre Strategie di Progettazione Antisismica", namely "GLIS - Isolation and Other Anti-Seismic Design Strategies"), which are both ASSISi corporate members. The first author of this paper was a member of the Scientific Committee of the conference (as GLIS President and ASSISi Founding President and present Vice-President), as well as key-note and invited lecturer for Italy (Martelli et al. 2013b, c). The text of this paper is partly based on the aforesaid contributions provided at Sendai by all its authors, but it also includes some further and more updated information.

According to the data made available the Sendai conference and to subsequent information received by the first author of this paper (Martelli 2013b), more than 23,000 structures in the world have been protected by passive anti-seismic (AS) techniques, such as seismic isolation (SI) or energy dissipation (ED) systems, shape memory alloy devices (SMADs), or shock transmitter units (STUs). They are located in more than 30 countries (see Fig. 14.1 and Table 14.1) and concern both new constructions and retrofits of existing structures of all kinds: bridges and viaducts, civil and industrial buildings, cultural heritage and industrial components and installations, including some High Risk (HR) nuclear and chemical plants and components. Buildings are made of all types of materials: reinforced 
Fig. 14.1 Numbers of seismically isolated buildings in the most active countries (data of September 2013)

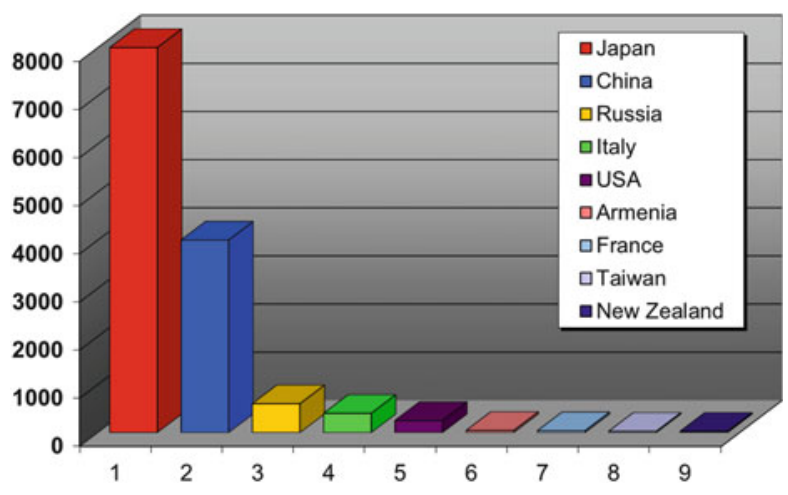

concrete (r.c.), steel and even wood (Eisenberg et al. 2011; JSSI 2013; Martelli and Forni 2010, 2011a, b; Martelli et al. 2008, 2011; Martelli et al. 2012a, b, c, 2013a, b, c, Mazzolani and Herrera 2012).

As shown by Fig. 14.1 and Table, 14.1, Japan is the leading country for the overall number of applications of the AS systems; it is followed by the Peoples' Republic (P.R.) of China, the USA, the Russian Federation and Italy (Fig. 14.2).

The use of the AS systems and devices in a civil context already includes not only the strategic structures (civil defence centres, hospitals) and the public ones (schools, churches, museums, commercial centres, hotels, airports), but also residential buildings and even many small and light private houses. Everywhere, the number of such applications is increasing, although it is strongly influenced by earthquake lessons and the availability and features of the design rules used.

As stressed by Martelli et al. (2013a, b), most SI systems rely on the use of rubber bearings (RBs), such as the High Damping natural Rubber Bearings (HDRBs), Neoprene Bearings (NBs), Lead Rubber Bearings (LRBs), or (especially in Japan) Low Damping Rubber Bearings (LDRBs) in parallel with dampers; in buildings, some plane surfaces steel-Teflon (PTFE) Sliding Devices (SDs) are frequently added to the RBs to support their light parts without unnecessarily stiffening the SI system (which would make it less effective) and (if they are significantly asymmetric in the horizontal plane) to minimize the torsion effects (the effects of the vertical asymmetries are drastically reduced by the quasi "rigid body motion" of the seismically isolated superstructure).

Another type of isolators, which has been used in Italy after the 2009 Abruzzo earthquake, is the so called Curved Surface Slider (CSS), which derived from the US Friction Pendulum (FPS) and the subsequent German Seismic Isolation Pendu$\operatorname{lum}(\mathrm{SIP})$.

Finally, rolling isolators (in particular Ball Bearings, BBs, and Sphere Bearings) are also applied: as mentioned by Martelli et al. (2013b), they are very effective and find numerous applications (more than 200) to protect buildings in Japan, but not in Italy, because there they have been judged too expensive (however, they have already been used, even in Italy, to protect precious masterpieces and costly equipment, including operating-rooms in hospitals). 


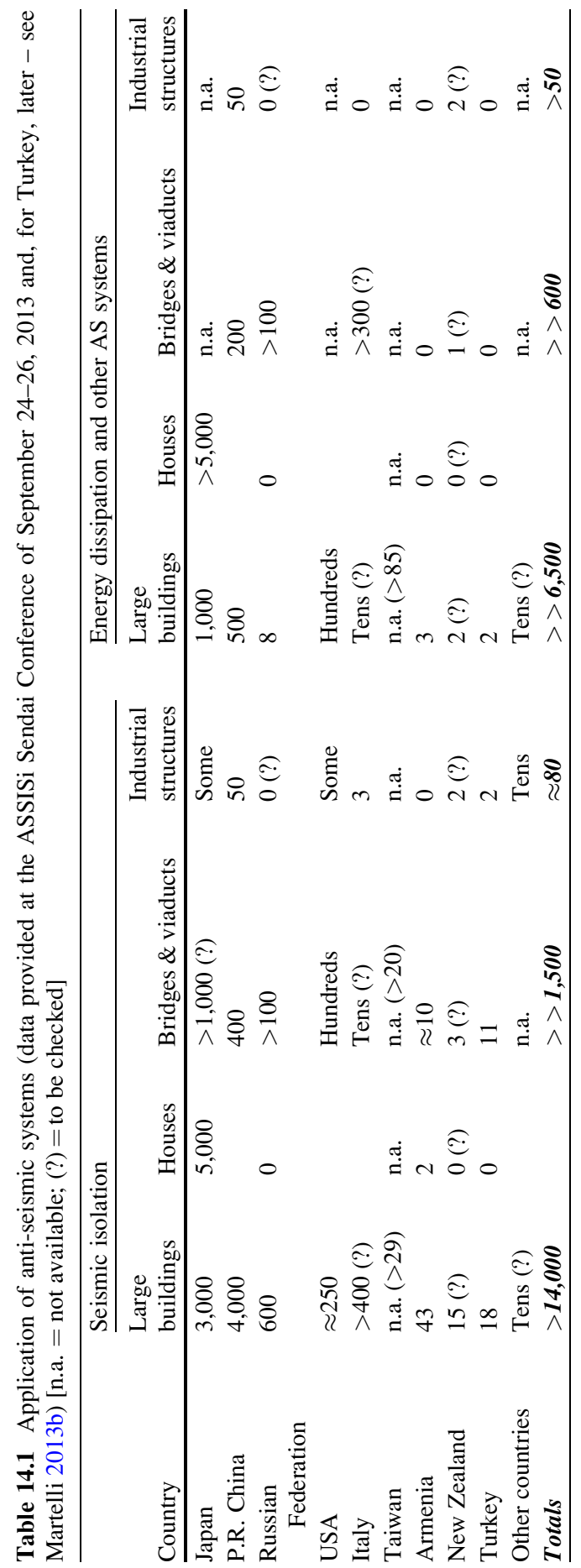


Fig. 14.2 Overall number of Italian buildings protected by seismic isolation during years

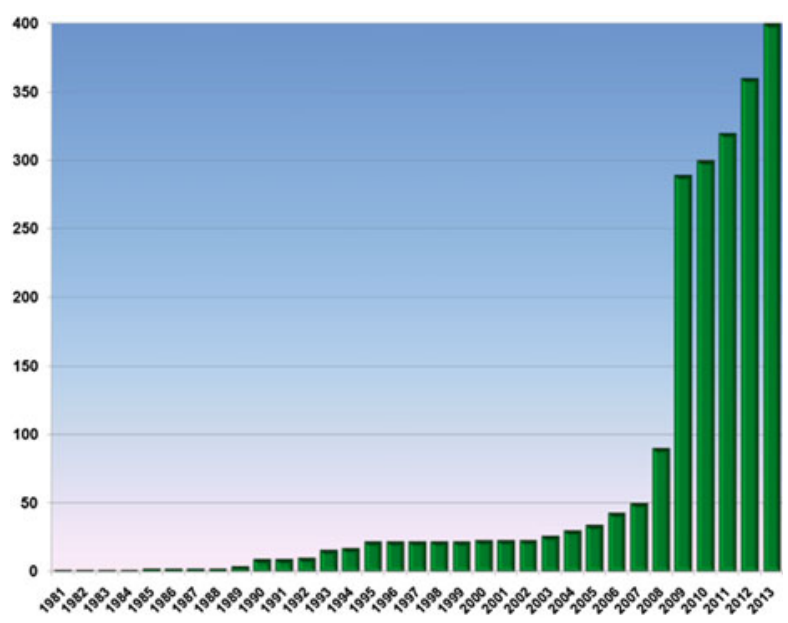

It shall be stressed that, to the knowledge of the authors, all structures protected by RBs that were located in areas hit by even severe earthquakes (including those struck by the 2011 Tohoku event in Japan, e.g. Figs. 14.3 and 14.4) exhibited an excellent behaviour, in spite of the fact that the violence of such earthquakes was frequently underestimated (Eisenberg et al. 2011; JSSI 2013; Martelli 2013b, 2014; Martelli and Forni 2010, 2011a, b; Martelli et al. 2011, 2012a, b, c, 2013a, b, c, 2014; Mazzolani and Herrera 2012; Zhou et al. 2013).

\subsection{Application of the Anti-seismic (AS) Systems}

\subsubsection{Application in Japan}

In Japan the first application of base SI dates back to 1983 (Eisenberg et al. 2011). Thanks to the availability of an adequate specific code since 2000, the free adoption of SI since 2001 (Martelli and Forni 2010) and the excellent behaviour of isolated buildings in violent earthquakes (Martelli et al. 2013a), this country is more and more consolidating its worldwide leadership on the use of the AS systems and devices. As shown by Fig. 14.1 and Table 14.1, the Japanese buildings or houses protected by SI, which were over 6,600 in 2011 (Martelli et al. 2013a), are now approximately 8,000 , while the large buildings provided with other type control systems are now approximately 1,000, against the 900 that had been reported by Eisenberg et al. (2011) in 2011 (in that year the latter systems were active or semi-active in 70 cases). Moreover, there are now more than 5,000 houses where ED systems have been installed (they were 2,000 in 2009, as reminded by Martelli et al. 2011).

More precisely, Japan is continuing the extensive adoption of the AS systems initiated after the excellent behaviour of two isolated buildings near Kobe during the 1995 Hyogo-ken Nanbu earthquake, of magnitude $\mathrm{M}=7.3$. This behaviour was 

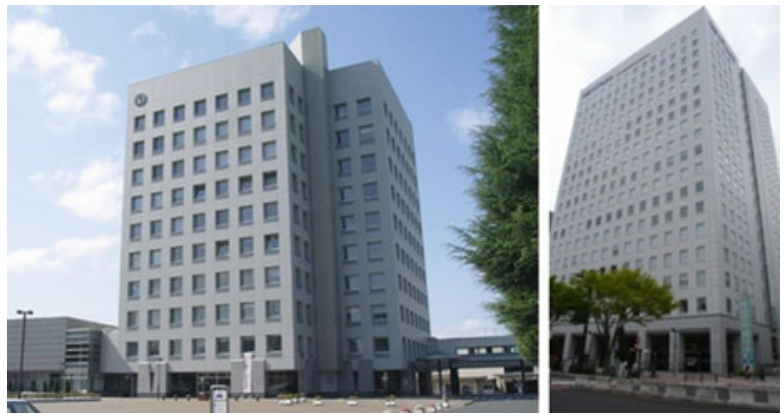

Fig. 14.3 Left: the seismically isolated 10-storey Hachinohe City Hall, near Sendai, isolated by means of LRBs. Right: the 18-storey MT Building in Sendai, isolated by means of RBs and SDs. Both buildings withstood the 2011 Tohoku earthquake undamaged (Eisenberg et al. 2011)

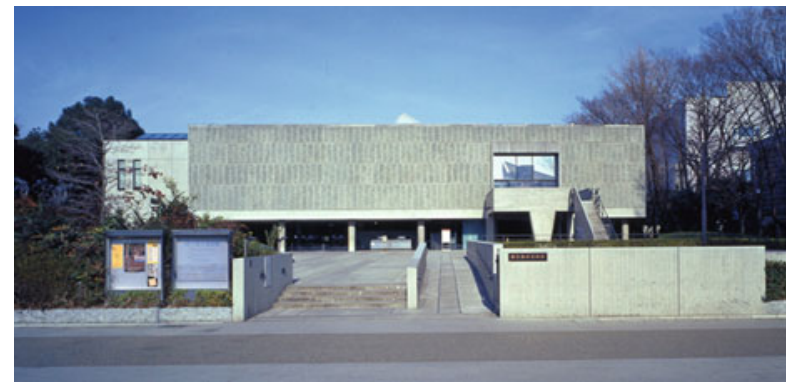

Fig. 14.4 The 4-storey National Western Art (Le Corbusier) Museum in Tokyo, retrofitted by inserting HDRBs in a sub-foundation in 1999. During the 2011 Tohoku earthquake the SI system reduced the PGA values in the two horizontal directions from 0.19 to $0.27 \mathrm{~g}$ at the base to 0.08 and $0.10 \mathrm{~g}$ at the top (Eisenberg et al. 2011)

confirmed by all Japanese buildings protected by SI during all severe events which followed that of 1995, namely those of Tokachi Offshore $(\mathrm{M}=8.0,2003)$, Niigata Chuetsu $(\mathrm{M}=6.8,2004)$, Fukuoka West Offshore $(\mathrm{M}=7.0,2005)$, Niigata Chuetsu Offshore $(\mathrm{M}=6.8,2007)$, Iwate-Miyagi Inland $(\mathrm{M}=7.2,2008)$ and Tohoku ( $\mathrm{M}=9.0$, 2011) (Eisenberg et al. 2011; Martelli et al. 2011, 2012a; Mazzolani and Herrera 2012).

Several buildings which withstood violent earthquakes prior to that of Tohuku were listed by JSSI (Kani 2008). With regard to the Tohoku earthquake, it is noted that the related seismic hazard was considerably underestimated, as for several previous violent events all over the world (Martelli et al. 2011, 2013a). In spite of this, most of the 118 isolated buildings located in the Tohoku area or erected in other Japanese sites behaved well, at least without considering the effects of the subsequent tsunami (see Figs. 14.3 and 14.4, as well as Martelli et al. 2013a). A similar behaviour was shown, for the isolated bridges and viaducts, by most of those protected by RBs (LRBs and HDRBs), although a certain number of them was later 
Fig. 14.5 The $91 \mathrm{~m}$ tall 20-storey building, with steel structure, of the Suzukakedai Campus of Tokyo Institute of Technology, protected by 16 RBs, 58 steel or oil dampers and by mega $\mathrm{X}$-shape braces, visible on the façade (Martelli et al. 2012a)
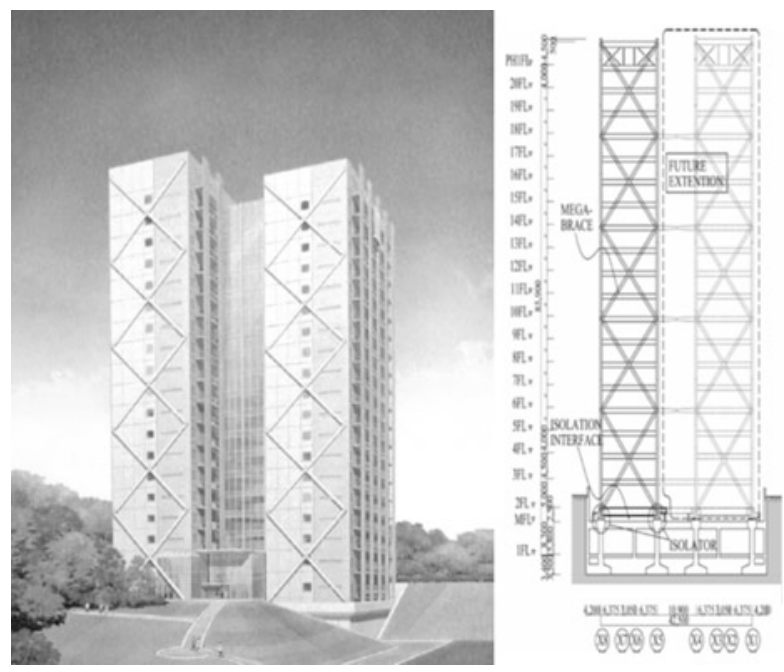

Fig. 14.6 Lateral view of a complex of twenty one 6- to 14-storey buildings, all erected on an unique "artificial ground" isolated at Sagamihara (Tokyo area) with 48 LRBs, 103 SDs and 83 BBs (Martelli and Forni 2010). This was the first Japanese application of "artificial grounds"

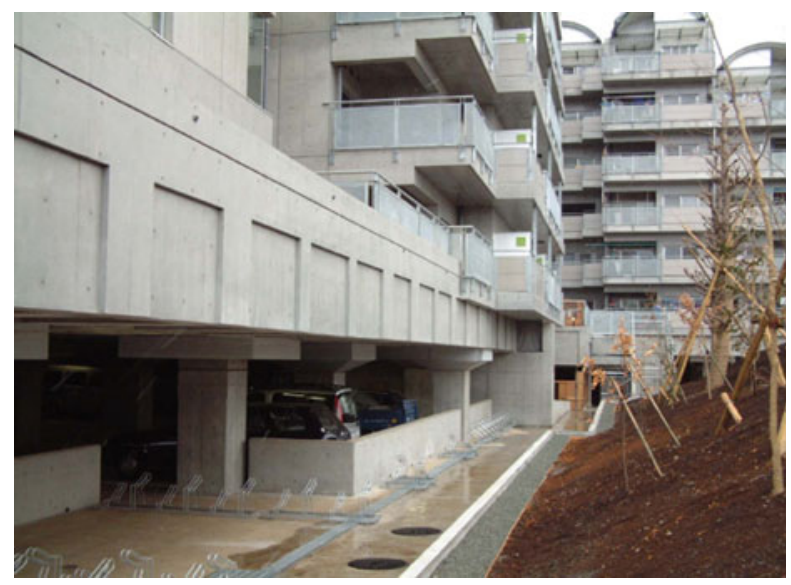

destroyed by the tsunami (due to deck rotation toward the upstream side, resulted from the uplifting force - see Martelli et al. 2013a).

Japanese, on the one hand, have confirmed the trend, initiated years ago, to isolate even high-rise buildings (Fig. 14.5) and sets of buildings supported by a common isolated r.c. structure (the so called artificial ground, a solution which enables large savings of construction costs - see Fig. 14.6) and, on the other hand, are more and more increasing the number of even very small private houses protected by SI (Martelli and Forni 2010). Based on data provided by JSSI, the isolated high-rise buildings are now rather numerous (they included 250 condominiums in the middle of 2011, as mentioned by Eisenberg et al. 2011). Furthermore, the isolated houses are already about 5,000; the latter were about 3,000 at the end of 2009 (Martelli and Forni 2010) and about 4,000 in the middle of 2011 (Eisenberg et al. 2011). More generally 
(Martelli et al. 2013a), in the middle of $201146 \%(1,100)$ of the Japanese isolated large buildings (e.g. excluding houses) were condominiums, $20 \%$ offices, $12 \%$ hospitals and $2 \%$ schools and most of these large buildings were new constructions (the retrofits of those existing were 90 some months ago).

The Japanese structures provided with ED systems include several high-rise buildings; these and the similarly protected private houses make use of various kinds of dampers (Martelli and Forni 2010): for instance, the applications of Buckling-Restrained Braces (BRBs) were already more than 250 in 2003. Moreover, approximately 40 Japanese buildings were seismically controlled by Tuned Mass Dampers (TMDs), of active or hybrid types, in June 2007, and so-called Active Damping Bridges (ADBs) were installed between pairs of adjacent high-rise buildings to reduce the seismic response of both of them, based on their different vibrational behaviours (Martelli and Forni 2010).

The use of the AS systems and devices also recently increased in Japan for the protection of cultural heritage and for that of bridges and viaducts (Martelli and Forni 2010; Martelli et al. 2011). For the latter it had began rather later than for buildings; it is being largely based on the use of HDRBs and LRBs and considerably extended especially after the Hygo-ken Nanbu earthquake, which struck Kobe in 1995 (by becoming obligatory for overpasses in this town).

Finally, as to the industrial installations, besides detailed studies for the SI (even with three-dimensional - 3D - systems) of various kinds of nuclear reactors, the Nuclear Fuel Related Facility was erected on 32 LDRBs and LRBs (Martelli and Forni 2010). Application of SI to large industrial factories also began in 2006: the first, concerning the fabrication of semi-conductors, was a 5-storey steel and SRC (mixed steel-concrete system) structure, with a height of $24.23 \mathrm{~m}$ and a total floor area of about $27,000 \mathrm{~m}^{2}$, which was built on LRBs, Viscous Dampers (VDs) and oil dampers; at least 2 further similar factories were also already in use at the end of 2009 (Martelli and Forni 2010; Martelli et al. 2012a).

\subsubsection{Application in the P.R. China}

In the P.R. China very ancient monasteries, temples and bridges, protected by means of rough sliding SI systems, are still standing, although they had to face numerous earthquakes, including very violent events, up to $M=8.2$; however, the application of modern SI systems began only in 1991 (Dolce et al. 2006). In any case, initially the SI systems, then the ED ones too have rapidly got a footing since that year, so that the isolated buildings were already 490 in June 2005, by leading the P.R. China to the third place at worldwide level for the number of applications, only slightly after the Russian Federation. Many of these applications were to dwelling buildings and no less than 270 to the masonry ones (Dolce et al. 2006).

At the end of 2006 the number of the Chinese isolated buildings had increased to more than 550 and included even rather tall constructions. Moreover: SI had already been applied to 5 further large span structures and 20 road and railway bridges or viaducts; 30 buildings were already protected by ED devices; 5 buildings 
and 6 bridges were already been provided with hybrid or semi-active seismic vibration control systems. SI had also already been used, for the first time in the P.R. China, to protect Liquefied Natural Gas (LNG) tanks (see Fig. 14.32 and Martelli and Forni 2010).

In 2007 the P.R. China passed the Russian Federation (Martelli and Forni 2010): in fact, the Chinese isolated buildings were 610 in May 2007 (against the approximately 600 declared at that time by the Russian experts - see Martelli and Forni 2010) and those protected by ED systems 45. The first included the so-called Isolation House Building on Subway Hub, completed near the centre of Beijing in 2006, which consists of 20 7- to 9-storey buildings, all separately isolated above an unique huge 2-storey isolated structure that contains all services and infrastructures, including railways and subways (Dolce et al. 2006). The objective of this application had been to optimize the use of a wide and valuable central area, which was previously occupied only by railway junctions and the subway, by also minimizing the consequent vibrations and noise: SI enabled saving $25 \%$ of construction costs, which made it possible to use the available budget for funding an average 3 storey rising of the 50 buildings. In the same years, Chinese application of 3D SI systems to civil buildings and of isolators or SMADs to cultural heritage had also begun (Martelli and Forni 2010).

In October 2008, the number of isolated Chinese buildings was about 650 . In November 2009 a further significant extension of the applications of the AS systems was reported in the P.R. China; in particular, the number of the newly erected isolated buildings per year doubled there after the violent Wenchuan earthquake of May 12, 2008 (moment magnitude $\mathrm{M}_{\mathrm{W}}=7.9$ ), by increasing from 50 to 100 per year (Martelli and Forni 2010).

This more rapid increase of the number of building applications of SI was due to both the excellent behaviour of two r.c. isolated buildings and even a 6-storey masonry one during the aforesaid earthquake (although its violence had been largely underestimated, by a factor 10 for the Peak Ground Acceleration - PGA) and the fact that the Chinese code (which still required the submission of the designs of the isolated buildings to the approval of a special commission) permitted to reduce the seismic loads acting on the superstructure and foundations of such buildings (Martelli and Forni 2010).

In November 2009 SI systems had been installed in the P.R. China in 32 bridges and 690 buildings, while 83 buildings had been protected by ED devices such as Elastic-plastic Dampers (EPDs), VDs or Visco-Elastic Dampers (VEDs), 16 by TMDs or other type dampers and 5 by semi-active or hybrid systems (Martelli and Forni 2010). The latter had also been installed in 8 bridges. SI has been applied in the P.R. China not only at the building base or at the top of the lowest floor, but also on more elevated floors (for risings or for erecting highly vertically asymmetric constructions), or at the building top (to sustain, in the case of retrofit, one or more new floors acting as a TMD), or also on structures that join adjacent buildings having different vibrational behaviours. More recent applications also included sets of buildings on artificial ground, base and roof SI of stadiums and the protection of valuable objects (e.g. electronic equipment and art objects) by means of SI tables (Martelli and Forni 2010). 
Fig. 14.7 Complex of dwelling buildings in SouthWestern P.R. China, formed by 824 - to 16 -storey seismically isolated buildings (overall floor area $=210,000 \mathrm{~m}^{2}$ ) (Eisenberg et al. 2011)

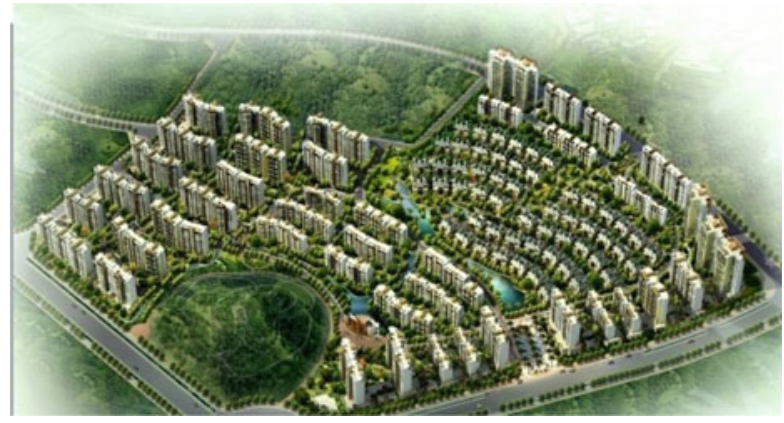

Fig. 14.8 Complex of dwelling buildings in SouthWestern P.R. China, formed by 94 4- to 6-storey seismically isolated buildings (overall floor area $=280,000 \mathrm{~m}^{2}$ ) (Eisenberg et al. 2011)

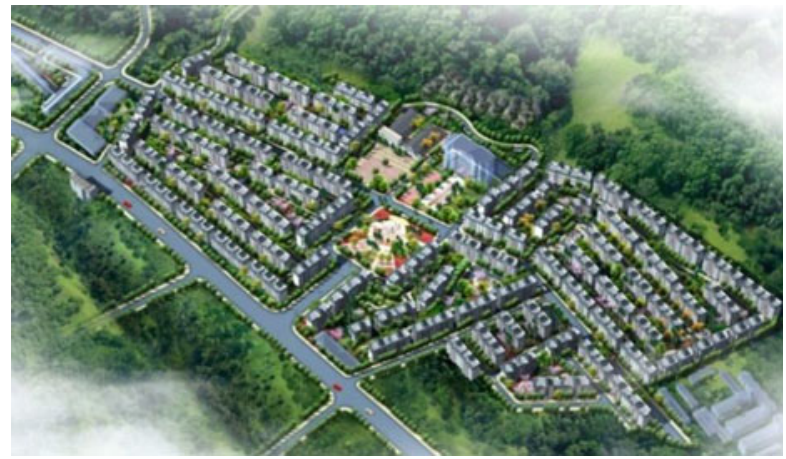

More recently, the number of applications of the AS systems really strongly increased in the P.R. China. In fact, it was reported by Eisenberg et al. (2011) that about 2,500 buildings and 80 bridges and viaducts had already been protected there by SI in September 2011, in addition to about 400 buildings and 50 bridges provided with dampers, 36 buildings or towers equipped with passive TMDs and 8 bridges and 5 towers with active or hybrid systems (note, for instance, the extensive building applications of SI shown by Figs. 14.7 and 14.8). Moreover, in the last 2 years, there was a further very significant increase of the aforesaid numbers: as shown by Table 14.1, SI has already been used in the P.R. China to protect 4,000 buildings, 400 bridges and viaducts and even 50 industrial structures (e.g. Fig. 14.32), while ED devices have already been installed in 500 buildings, 200 bridges and viaducts and further 50 industrial structures (Zhou et al. 2013; Martelli 2013b).

It is worthwhile stressing that the effectiveness of SI for the protection of buildings and, in particular, of schools and hospitals was recently confirmed in the P.R. China during the Lushan earthquake $\left(\mathrm{M}_{\mathrm{W}}=7.0\right.$ ) of April 20, 2013 (Zhou et al. 2013). This earthquake occurred in an area that had already been affected by the violent Wenchuan event in 2008 (the distance between the two epicentres was $150 \mathrm{~km}$ ) and was characterized by PGA values that reached $0.4-0.6 \mathrm{~g}$, compared to the design value of $0.3 \mathrm{~g}$ (note, for this earthquake too, similar to previous events mentioned by Martelli et al. 2013a, the inadequacy of the probabilistic approach used 

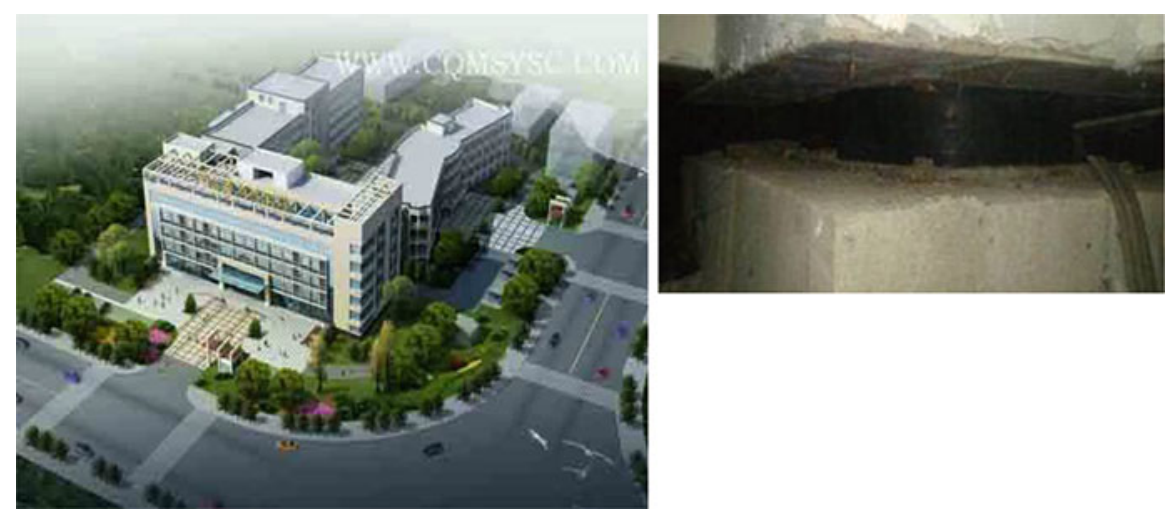

Fig. 14.9 View of the Lushan county hospital (China), before the earthquake of April 20, 2013 (Zhou et al. 2013)

to define this design value, and the fact that the new event occurred only 5 years after that of Wenchuan, while the latter was preceded by an earthquake of magnitude comparable nearly 80 years earlier).

The Lushan event caused 196 deaths (besides 21 missing people) and the wounding of 250,000 people. About 40,000 buildings (i.e. about $75 \%$ of those in the area affected by the earthquake) collapsed or were damaged. The heavily damaged buildings included numerous strategic and public buildings (including schools and hospitals), even constructed or reconstructed after the Wenchuan event. However, where it was used, SI showed, once again, an excellent effectiveness.

Particularly interesting were, in Lushan, two cases of r.c. structures:

- that of two primary schools, the first conventionally founded, the other base isolated, both provided with a seismic monitoring system;

- that the county hospital (7 floors above ground and one basement), consisting of two buildings with conventional foundations and one with base SI.

About the two schools, while for that conventionally founded the PGA value of $0.2 \mathrm{~g}$ was amplified, at the roof, to $0.72 \mathrm{~g}$, for that with SI the aforesaid value was reduced to $0.12 \mathrm{~g}$. Thus, the effectiveness of SI can be quantified in a reduction factor of the roof maximum acceleration equal to 6 .

As to the county hospital (Fig. 14.9), the two buildings with conventional foundations suffered damage to both partitions, roof and equipment contained, which made them unusable after the earthquake (Fig. 14.10); on the contrary, the seismically isolated block was the only hospital building of the county to be remain fully undamaged and operational (Fig. 14.11): this allowed to heal thousands injured people, which was impossible in other hospitals in Lushan. 

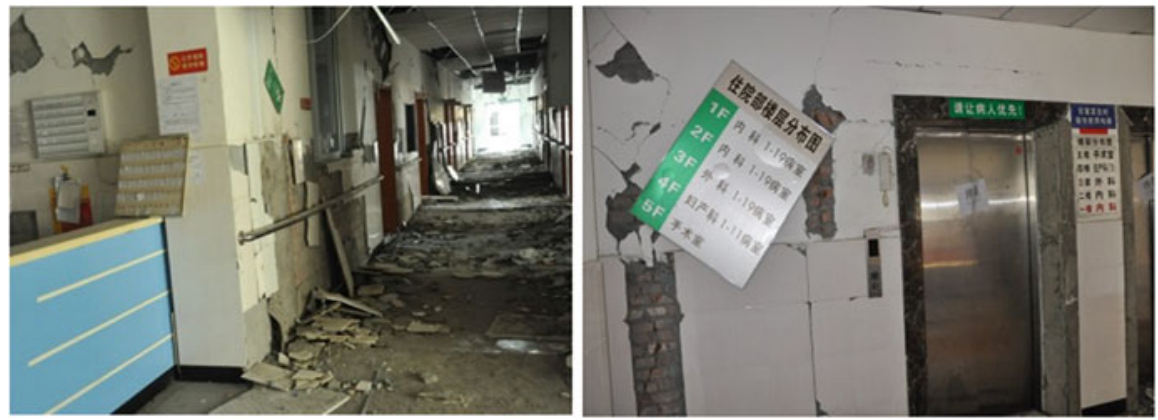

Fig. 14.10 Damage suffered by the two conventionally founded buildings of the hospital of Fig. 14.9 (Zhou et al. 2013)
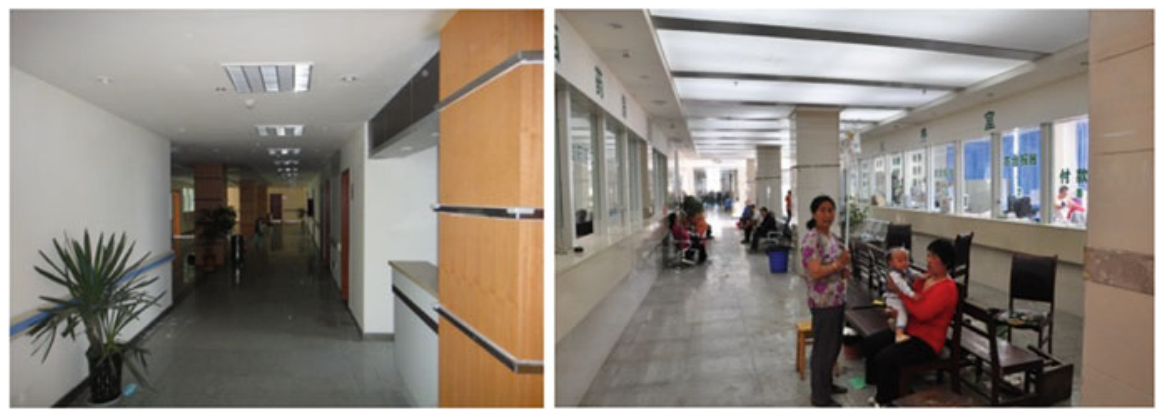

Fig. 14.11 Full integrity and operability of the isolated building of the hospital of Fig. 14.9 (Zhou et al. 2013)

\subsubsection{Application in the Russian Federation}

The Russian Federation is third for the number of seismically isolated structures. As shown by Table 14.1, there are about 600 applications of SI to buildings and more than 100 to bridges and viaducts (according to the information provided by Eisenberg et al. 2011, the overall number of isolated structures was about 550 in September 2011). In addition, there is already a significant number of structures (especially bridges) protected by ED systems (Table 14.1). The use of modern SI systems, formed by RBs, frequently in conjunction with SDs and/or dampers (similar to those adopted in the other countries), is going on replacing that of the previous so called low cost isolators (reversed mushroom-shaped r.c. elements), which had been installed since the years 1970s. After the retrofits of some important historical buildings (Dolce et al. 2006; Martelli et al. 2008; Sannino et al. 2009), recent Russian application includes even high-rise buildings, in particular in Sochi, the site of the 2014 Winter Olympic Games. For some of these, Italian HDRBs have also been used, as shown by Figs. 14.12 and 14.13 (Eisenberg et al. 2011; Martelli et al. 2011). 

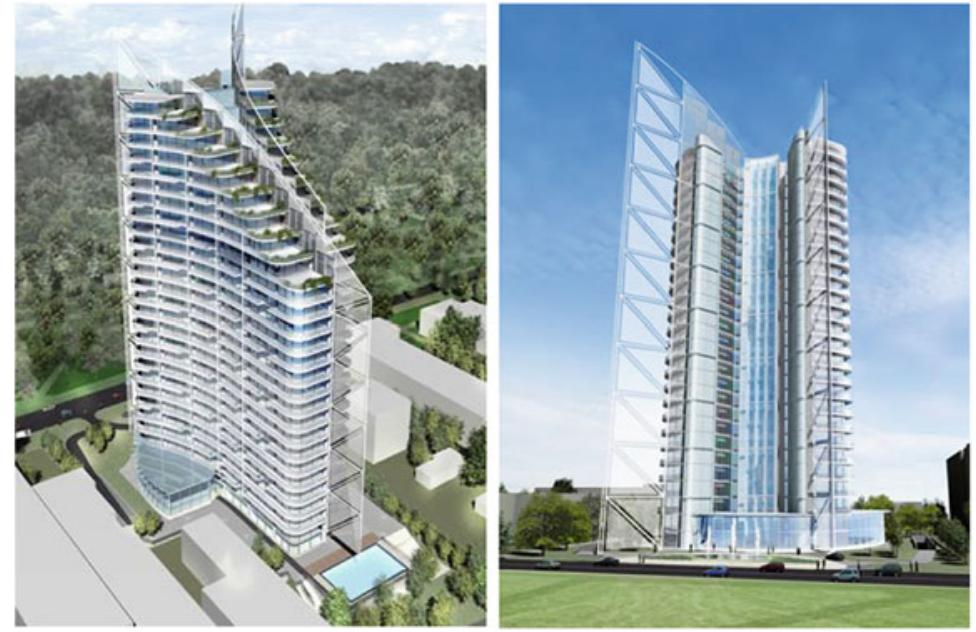

Fig. 14.12 Design of the base-isolated Hayat (Sea Plaza) Hotel, a 28-storey r.c. building (with 2 underground floors), $93.6 \mathrm{~m}$ tall and with a total floor area of $40,000 \mathrm{~m}^{2}$, erected in Sochi (Russia) (Eisenberg et al. 2011)

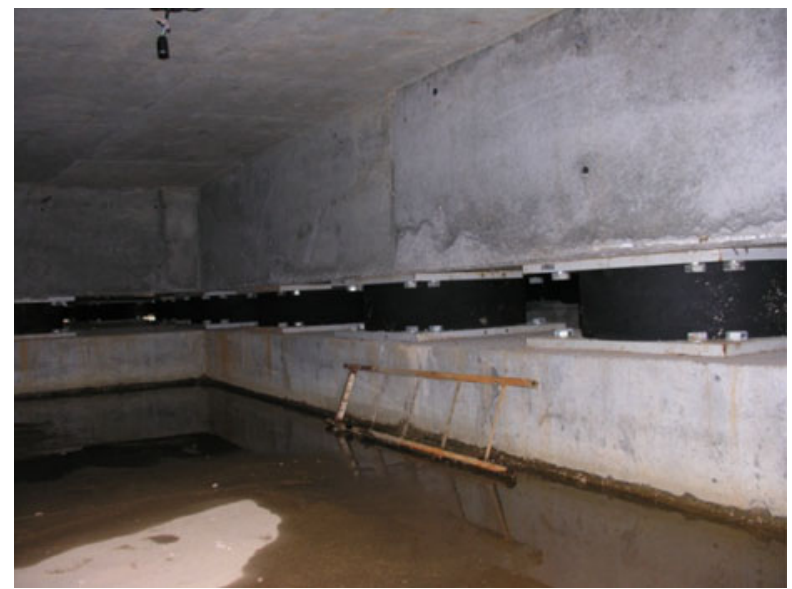

Fig. 14.13 Some of the $193 \mathrm{HDRBs}$, manufactured in Italy, which protect the building of Fig. 14.12 (picture taken on September 23, 2011, during the 2011 Sochi Conference) (Martelli et al. 2012a)

\subsubsection{Application in the USA}

As shown by Table 14.1, the USA remain at the third place, after Japan and the P.R. China, for the overall number of applications of the AS systems and devices (Eisenberg et al. 2011; JSSI 2013). In this country, however, such applications go on being satisfactorily progressing only for bridges and viaducts and for buildings 
protected by ED systems. They concern both new constructions and retrofits. More precisely, at the end of 2009, HDRBs, LRBs and, more recently, ED devices and STUs had already been installed in about 1,000 U.S. bridges and viaducts, located in all U.S. states, while over 1,000 buildings had been provided with dampers of various kinds (Martelli and Forni 2010): VDs and friction dampers (FDs) already protected approximately 40 and, respectively, 12 buildings in 2001 and BRBs 39 further buildings in 2003 (Dolce et al. 2006).

On the contrary, as far as SI of buildings is concerned, the number of new applications remains still limited (recently 3 or 4 per year), in spite of the excellent behaviour of some important U.S. isolated buildings during the 1994 Northridge earthquake (Dolce et al. 2006) and the long experience of application of this technique to such structures (since 1985). This is a consequence of the very penalizing design code in force in the USA for the isolated buildings: these were not more than 200 in September 2011 and are now approximately 250, although the related applications are mostly very important and half of them are retrofits, even of monumental buildings (Martelli and Forni 2010).

SI of US buildings has been performed using HDRBs, LRBs (in some cases in conjunction with LDRBs, SDs, VDs and other ED devices) and, later, the FPS too. With regards to the design earthquake levels adopted in California, Martelli and Forni (2010) stressed that they correspond very large magnitudes (e.g. $M=8.3$ for the new 911 Emergency Communications Centre erected in San Francisco in the years 1990s and $\mathrm{M}=8.0$ for the San Francisco City Hall retrofitted with 530 LRBs in 2000): this imposes the use of SI (as the only possibility) for these applications, in spite of its large implementation cost in the USA.

\subsubsection{Application in Italy}

Fifth (after Japan, the P.R. China, the Russian Federation and the USA) and first in Western Europe for the overall number of applications of the passive AS devices remains Italy (Figs. 14.1 and 14.2 and Table 14.1). There, the use of the AS systems began in 1975 for bridges and viaducts and in 1981 for buildings (Dolce et al. 2006; Eisenberg et al. 2011; Martelli et al. 2008, 2012c). It is worthwhile stressing that the design of the first two Italian suspended buildings protected by AS systems, located in Naples, had been completed before the 1980 Campano-Lucano earthquake, when the Naples area was not yet considered as seismic: after such an event, that area was classified in "seismic category 3" (i.e. with moderate seismic hazard): thus, in order to avoid large modifications of the buildings designs, NBs were added on the roof of such buildings, together with other passive AS devices inside them (Dolce et al. 2006; Martelli et al. 2012a, b).

In spite of the aforesaid pioneering role of Italy in the development and application of the passive AS systems, in the years 1990s their use remained rather limited several years long, due to the lack of design rules to the end of 1998, then due to their inadequacy and a very complicated and time-consuming approval 


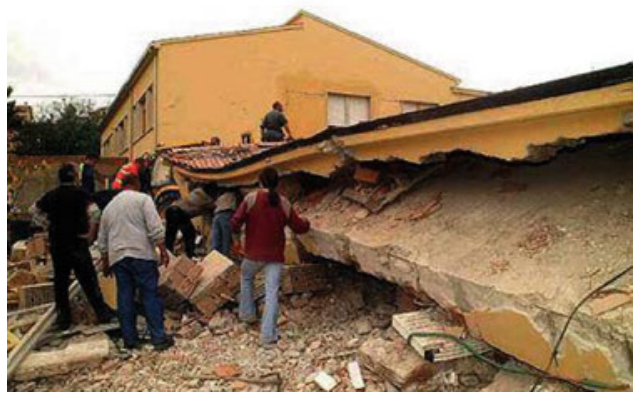

Fig. 14.14 Francesco Jovine school of San Giuliano di Puglia, after its collapse during the 2002 Molise \& Puglia earthquake $(\mathrm{M}=5.9)$
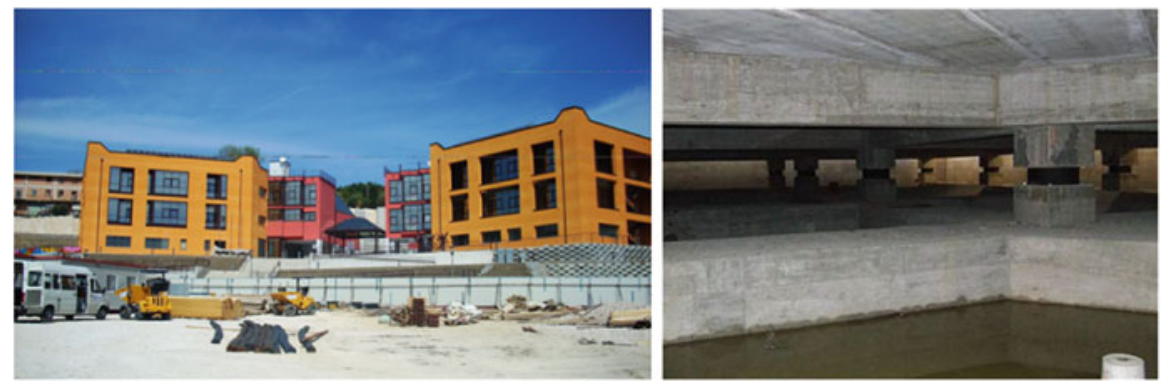

Fig. 14.15 Left: the isolated complex including the new Francesco Jovine primary school and "Le Tre Torri" Poly-Functional Centre in San Giuliano di Puglia (Campobasso), in 2008. Right: view of some the isolators supporting their common base slab
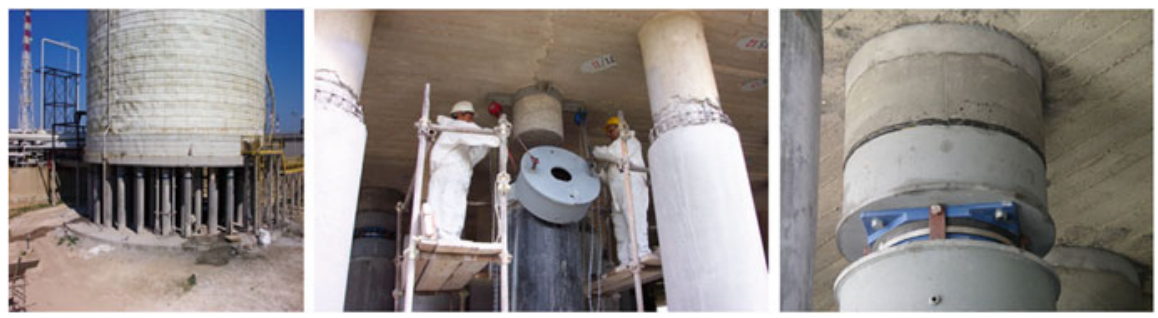

Fig. 14.16 One of the three tanks of the Company Polimeri Europa of the Italian ENI Group located in Priolo, which were seismically retrofitted using U.S. FPS devices in the years 20052008 and one of the isolators during and after its installation. To the knowledge of the authors, this is the only application of SI to chemical plants and components so far existing in Italy (prior to the 2009 Abruzzo earthquake, it was also the only application of CSS devices in Italy)

process to 2003 (Dolce et al. 2006). However, significant application of the passive AS systems (especially of SI) restarted in Italy about 10 years ago, initially as a consequence of the collapse of the Francesco Jovine primary school in San 


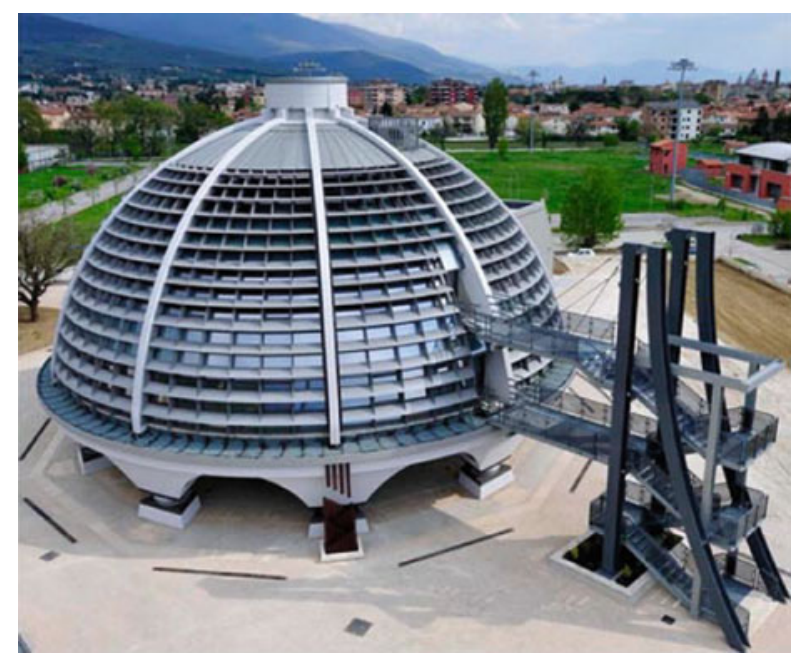

Fig. 14.17 Main building of the Civil Defence Centre of Foligno (Perugia), former seismic zone 1, isolated by 10 HDRBs and certified as safe by A. Martelli in 2011
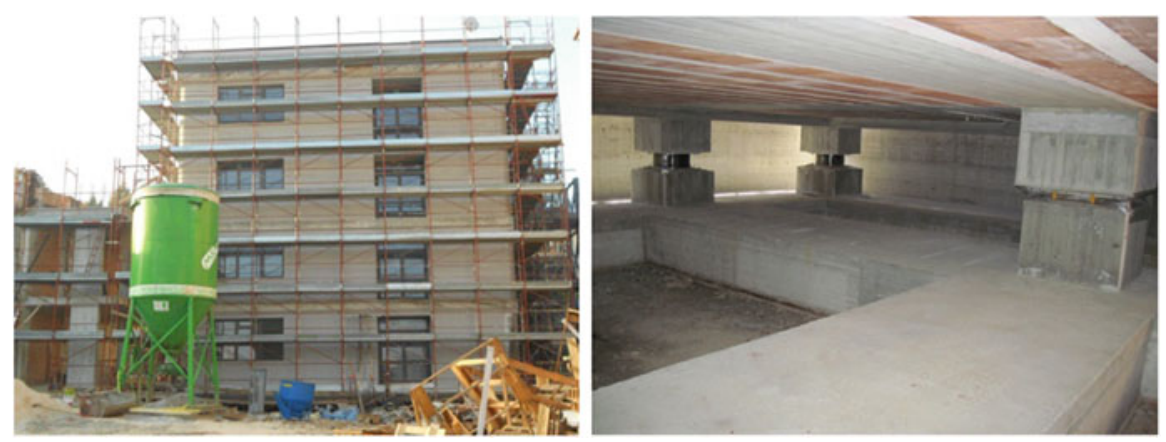

Fig. 14.18 The new block B of the Romita High School for scientific studies in Campobasso (former seismic zone 2), isolated by $12 \mathrm{HDRBs}$ and $10 \mathrm{SDs}$, which was reconstructed with SI, after its demolition in 2010 (blocks A and B had been found unsafe by ENEA, CESI and the University of Basilicata in 2003 - see Fig. 14.29). The safety of the new building was certified by A. Martelli in 2013

Giuliano di Puglia (Campobasso) during the 2002 Molise \& Puglia earthquake (Fig. 14.14) and the subsequent enforcement of a new national seismic code (in May 2003), which freed and simplified the adoption of the AS systems in Italy (see Figs. 14.15, 14.16, 14.17, 14.18, and 14.19, Martelli et al. 2008, 2013b; Martelli and Forni 2010).

The use of SI became particularly rapid especially after the Abruzzo earthquake of April 6, 2009, as a consequence of the large damage caused by this event to the conventionally founded structures and cultural heritage (Martelli and Forni 2010, 2011b). Thus, in 2009, Italy overtook the USA for the number of seismically 


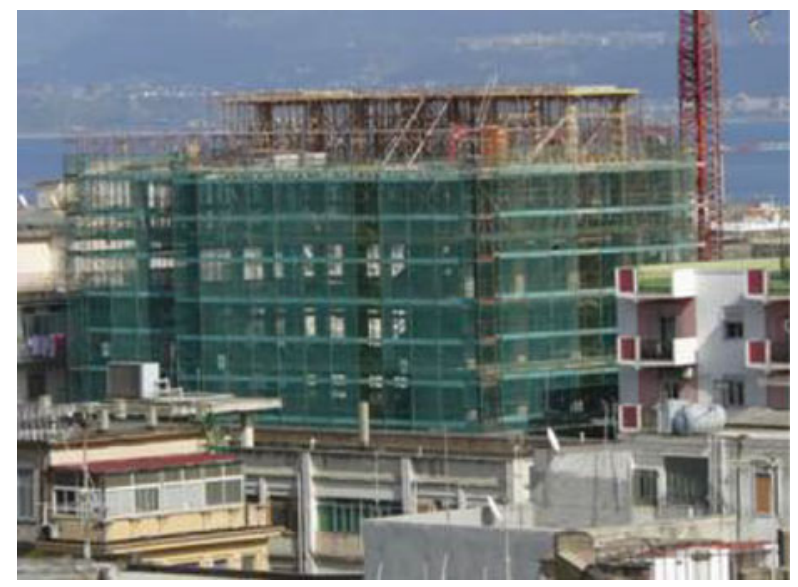

Fig. 14.19 Eight-storey isolated building which is nearing completion in Messina on 22 LDRs and 2 SDs. Its structural safety will be certified by A. Martelli in 2014
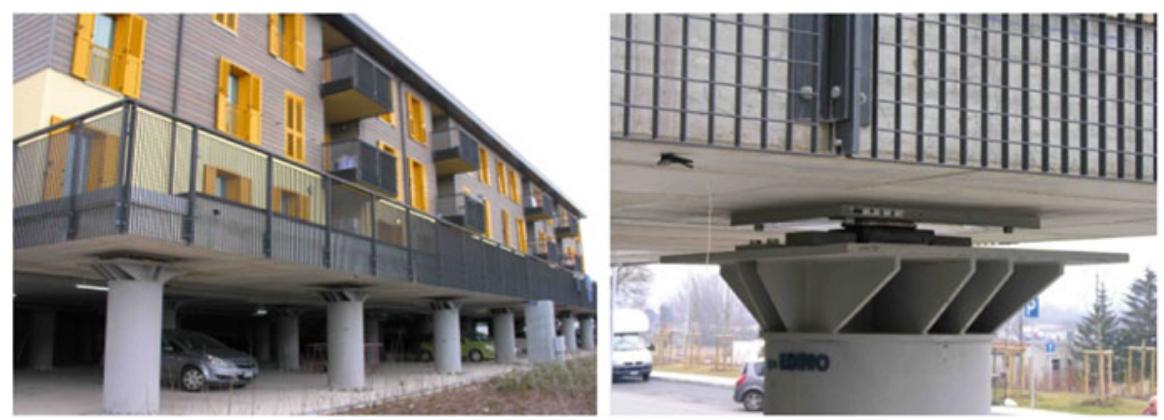

Fig. 14.20 Left: one of the 184 pre-fabricated houses (wood, or r.c., or steel structures) erected in L'Aquila to host up to 17,000 residents who remained homeless after the 2009 Abruzzo earthquake. Right: detail of one of the 40 CSS devices, manufactured in Italy, which have been installed at the top of columns (made of steel or r.c.) to isolate the supporting slabs of such houses

isolated buildings (although not for their importance): those in use were about 70 before the aforesaid earthquake, with further $20 \div 30$ under construction or design, while they are now more than 400 and several further applications to new-built and retrofitted structures of these kinds are in progress (Martelli and Forni 2011b; Martelli et al. 2012a, 2013b).

The recent applications of SI include 184 wood, r.c. or steel pre-fabricated houses erected in L'Aquila, each on a large isolated r.c. slab (Fig. 14.20), to provisionally host up to 17,000 homeless residents (at least in the first years). These were seismically isolated, for the first time in Italy, using CSS devices manufactured in the country (Fig. 14.20). However, the use of the traditional HDRBs or LRBs, in conjunction with some SDs, is also going on, in both L'Aquila 

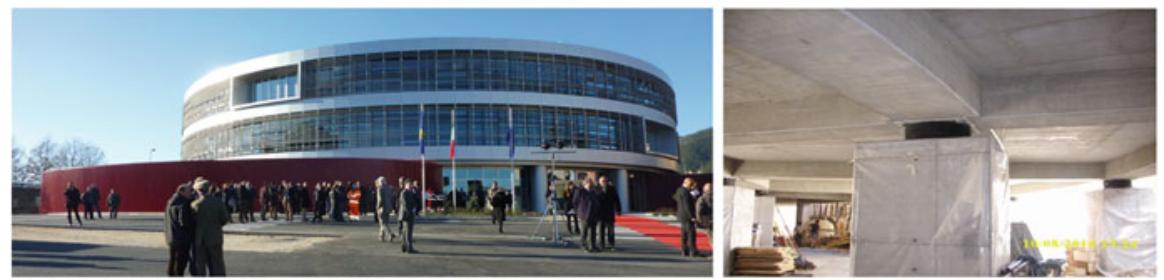

Fig. 14.21 Left: the new Headquarters of ANAS (National Agency for Roads Construction) in L'Aquila, erected on 60 HDRBs after the 2009 Abruzzo earthquake (which had severely damaged the previous headquarters building), completed at the beginning of 2011. Right: view of some of its isolators
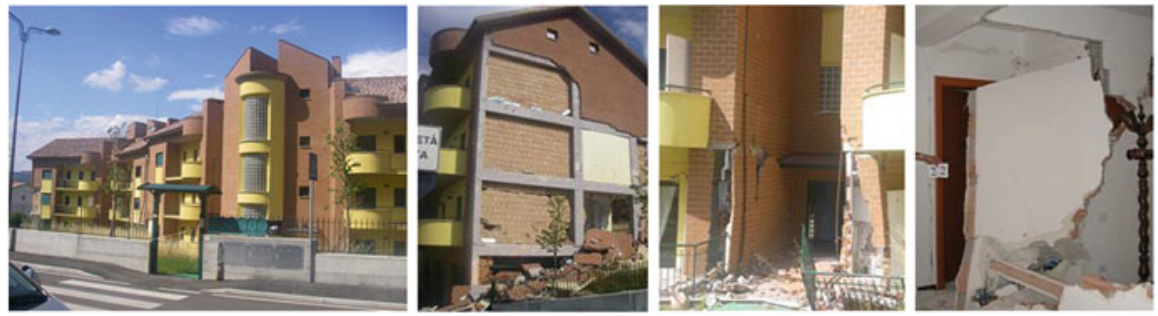

Fig. 14.22 Left: the dwelling building complex (3 buildings) of Via Borgo dei Tigli 6-8-10 in L'Aquila (Pianola area), which had been just completed before the 2009 Abruzzo earthquake. Right: damage caused to the building by this event
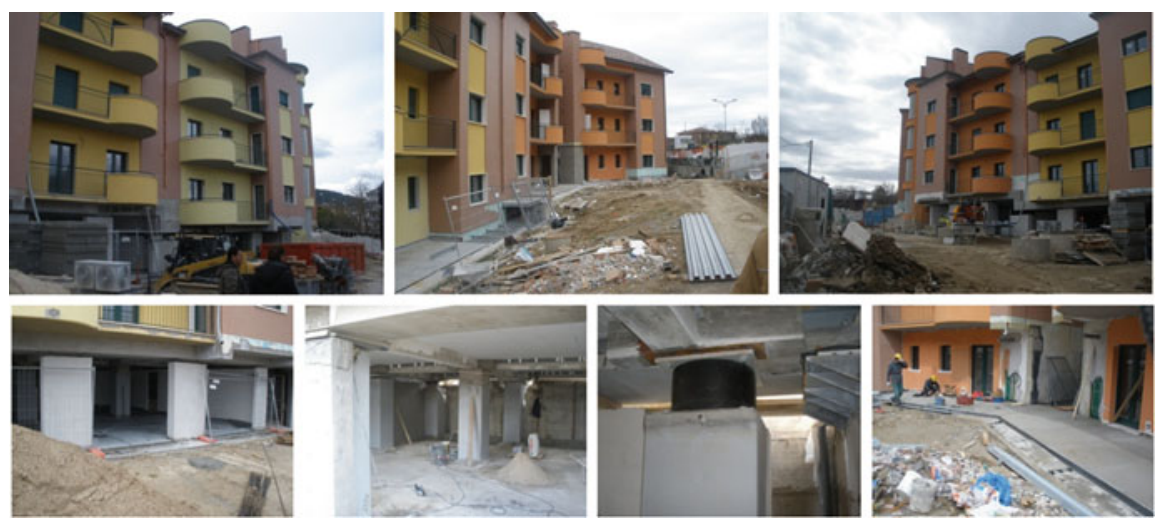

Fig. 14.23 Seismic retrofit of the building complex of Fig. 14.22, performed by means of $42 \mathrm{HDRBs}$ and 62 SDs and connection of the originally separated three buildings. The structural safety will be certified by A. Martelli in 2014

and other Italian sites, for several new constructions and retrofits (see, for instance, Figs. 14.21, 14.22, 14.23, and 14.24, Martelli et al. 2011, 2013b; Martelli and Forni 2011a, b). In particular, the new Francesco Jovine school (Fig. 14.15), protected by 


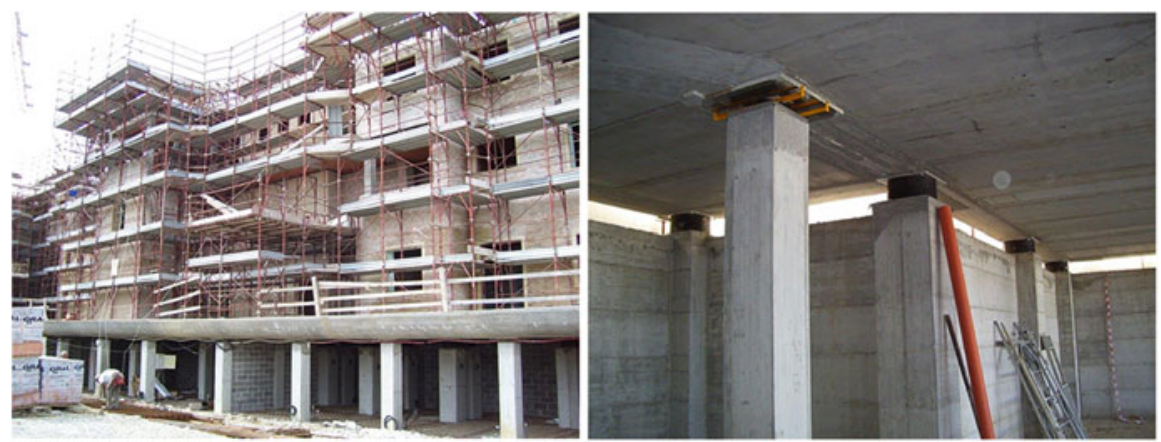

Fig. 14.24 Left: seismically isolated dwelling building complex under construction in Ozzano Emilia (Bologna), irregular in shape $(61 \mathrm{~m} \times 28 \mathrm{~m} ; 2$ buildings with 2 staircases, connected to the second floor; 4 isolated above ground isolated floors, with the isolators installed in the non-isolated basement). Right: some of the isolators of the building (61 HDRBs and $56 \mathrm{SDs}$ )

a SI system designed with the cooperation of ENEA (Italian National Agency for New Technologies, Energy and Sustainable Economic Development) and formed by 61 HDRBs and 13 SDs, which was the first Italian isolated school (certified as safe by the first author of this paper in September 2009), has been followed by several further projects of this kind: the seismic protection of schools by means of SI, besides that of hospitals and other strategic structures, is now a "priority 1" objective of GLIS (Martelli and Forni 2010; Martelli and Forni 2011a, b).

Moreover, the use of the AS systems is going on for bridges and viaducts (those with such systems were already at least 250 in 2009), as well as for cultural heritage (Martelli 2009; Martelli and Forni 2010, 2011a, b, Martelli et al. 2008, 2011). For the latter, the application of new retrofit techniques using SI, applicable to monumental buildings (Martelli 2009; Clemente et al. 2011), has also been planned for both reconstructing L'Aquila and for enhancing the seismic protection of some ancient constructions in Sulmona, an historic town close to L'Aquila which was not damaged by the 2009 event, but is also very earthquake-prone. This method (Fig. 14.25) consists in the lateral insertion of large diameter tubes below the building, inside which the isolators will be inserted. The applications planned in Sulmona will be made in the framework of a collaboration agreement signed between ENEA and the local municipality, which will entrust ENEA with the check of the retrofit designs and supervision of the subsequent construction works (Martelli et al. 2011).

\subsubsection{Application in Other Countries}

The countries which follow Italy for the overall number of applications of the AS systems are South Korea, Taiwan, Armenia, New Zealand, France, Turkey, Mexico, Canada, Chile and others (Martelli and Forni 2010, 2011b): many applications in 

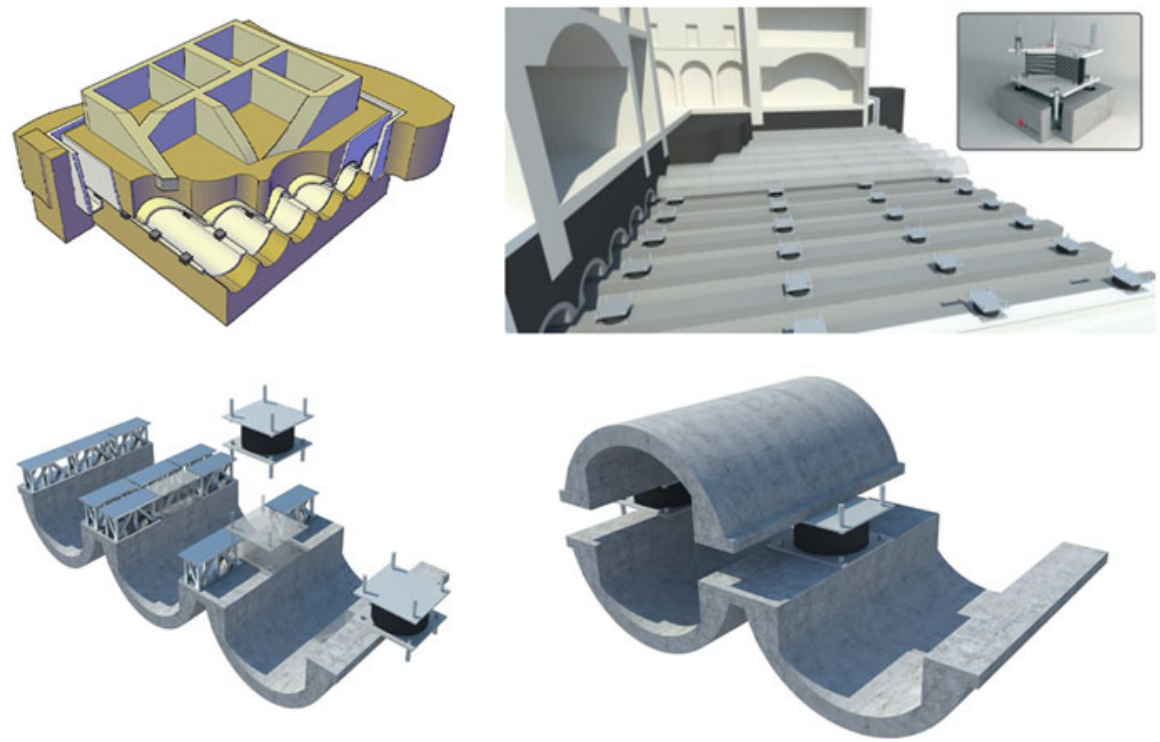

Fig. 14.25 System patented by ENEA and Polytechnic of Torino for the retrofit with SI of monumental buildings, performed by laterally inserting tubes (which will contain the isolators) below the foundations (Clemente et al. 2011; Salvatori 2013)

these countries make use of Italian AS devices (e.g. in Turkey, Greece, Portugal, Spain, Iran) and some (in Romania, Cyprus) have also been designed by Italians (Martelli et al. 2012a).

Armenia, with 45 completed isolated buildings and others under construction (see Table 14.1 and Martelli 2013b), remains second, at worldwide level, for the number of applications of such devices per number of residents, in spite of the fact that it is a still developing countries. In New Zealand, one of the motherlands of AS devices (in particular of those based on the use of lead, like LRBs and LDs) and third in the world for the number of applications of such devices per number of residents, the isolated structures had an excellent behaviour in both the 2010 Canterbury earthquake, of $\mathrm{M}=7.1$, and the 2011 Christchurch event, of $\mathrm{M}=6.3$ (Martelli and Forni 2011b; Mazzolani and Herrera 2012; Martelli et al. 2011, 2012a). Similarly, the isolated structures in Santiago had an excellent behaviour in Chile too, during the magnitude 8.8 Maule earthquake of February 27, 2010 (Eisenberg et al. 2011; Martelli and Forni 2011b; Martelli et al. 2011; Mazzolani and Herrera 2012). 


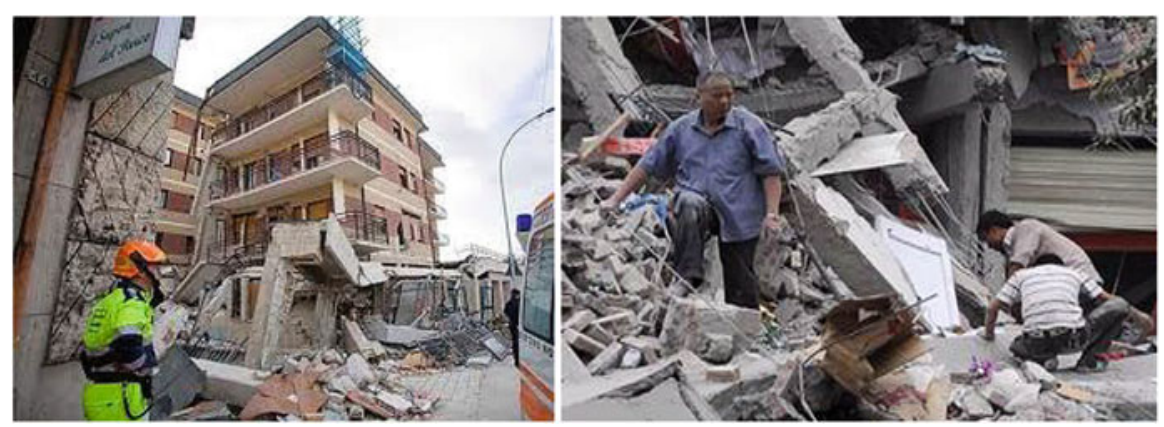

Fig. 14.26 Left: the "Student House" in L'Aquila, collapsed during the Abruzzo earthquake of April 6, $2009(\mathrm{M}=6.2)$, causing the death of eight students. Right: secondary school in Dujiangyan (P.R. China), collapsed during the Wenchuan earthquake of May 12, 2008 $(\mathrm{M} \approx 8.0)$, causing the death of 900 students

\subsection{Benefits of the as Systems for the Protection of Schools, Hospitals, Cultural Heritage and HR Plants}

Schools and hospitals are the strategic and public buildings that should guarantee the highest level of safety. In fact, schools host the most valuable asset of a community, that is its future, while hospitals shall remain fully operational after all catastrophic events (Martelli et al. 2013c, d). This means that, for any accidental event that may hit them, the total integrity of schools and hospitals must be ensured, namely not only that of the structural elements, but also that of the non-structural ones (partitions, claddings, ceilings, plants, contained objects and equipment and, especially, the occupants, namely, for schools, students, teachers and school staff). To achieve this goal for existing buildings, the so-called "seismic improvement" is insufficient: it is indispensable that such buildings are put in the same safety conditions as those obtainable for the new constructions. The aforesaid remarks obviously apply to the other kind strategic and public structures too; among these, the seismic protection of museums is particularly important in Italy, because this country hosts a large part of the cultural heritage existing in the word.

However, even recent experience shows that too many schools, too many hospitals, too many museums and too many other kind strategic and public structures, both in Italy and in other countries, are very unsafe, especially (but not only) in the case of earthquakes (see, for instance, Figs. 14.14 and 14.26 for schools and Fig. 14.10 for hospitals).

In addition, as stressed by Martelli $(2012,2013 \mathrm{c})$, it should be obvious to all that the High Risk (HR) plants too should be adequately protected from natural disasters, primarily from earthquakes and other accidental events that can be triggered by them (in particular by tsunamis, caused by violent earthquakes with epicentres in the sea or even, if these are close to the coast, on the ground). The HR plants include 

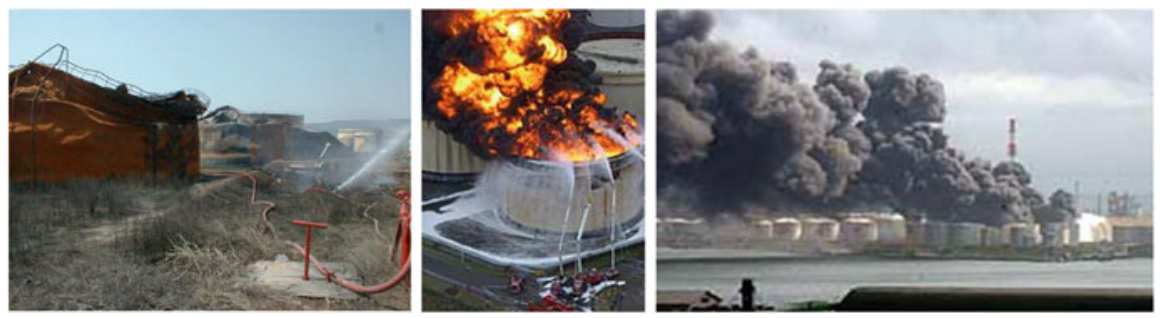

Fig. 14.27 Left: rupture of a storage tank in the Yarimca Refinery (Turkey), owned by Tupras, during the Izmit earthquake of August 17, $1999\left(\mathrm{M}_{\mathrm{W}}=7.4\right)$, which caused 17,000 victims. At the centre: initial fire of one the two tanks (the first containing crude oil, the second naphtha) of the Tomakomai City petrochemical installation (Japan), caused by the two main shocks of the Off Tokachi earthquake of September 26 and 28, $2003(\mathrm{M}=8.0$ and $\mathrm{M}=7.1)$, with epicenters at $220 \mathrm{~km}$ from the plants. Right: propagation of the fire in the Tomakomai City petrochemical installation, during the aforesaid quake, with the consequent damage of 45 tanks (30 severely, 29 with leakage) of the 105 present

not only the nuclear ones, but also several types of chemical installations and components: in particular the Liquefied Natural Gas (LNG) tanks, which are large in size (with volumes up to $150,000 \mathrm{~m}^{3}$ or more), and also the smaller spherical or cylindrical storage tanks that are present, for example, in petrochemical plants, the danger of which is an increasing function of their (often large) number in each installation (Martelli 2012). A substantial amount of these tanks already suffered serious damage in several countries, during a significant number of seismic events (see Fig. 14.27 and Martelli 2012).

With regard to earthquake protection of both schools and HR plants and components (as well as of other types of structures), SI, ED and the other types AS technologies have been demonstrated to be extremely efficient (Martelli et al. 2013a, b). However, their wide use (which obviously frequently entails the acceptance of some additional construction costs) requires a correct perception of the seismic risk, which does not yet exist in countries like Italy. For this reason, besides continuing to promote the development and application of the AS systems (Martelli et al. 2013a, b), the Italian association GLIS and ENEA are devoting great efforts to raise public awareness and to stimulate institutions to start in Italy, at last, an adequate seismic prevention policy (Clemente and Martelli 2013; Martelli 2013a; Martelli et al. 2013b, c, d).

As mentioned by Martelli (2012, 2013c), this campaign was undertaken for the protection of the HR chemical plants and components several years ago, due to the presence of several installations of this kind in Italian areas that are characterized by high seismic hazard (Fig. 14.28) and was soon extended to the civil constructions, well before the Emilia earthquake of May 20, 2012 (Martelli 2012, 2013c; Martelli et al. 2013d). It has been brought to the attention of the Italian institutions for a long time (especially of that of the 8th Commission on Environment, Territory and Public Works of the Italian Chamber of Deputies - see Martelli et al. 2013b). This first occurred for the issues related to HR chemical plants and components 

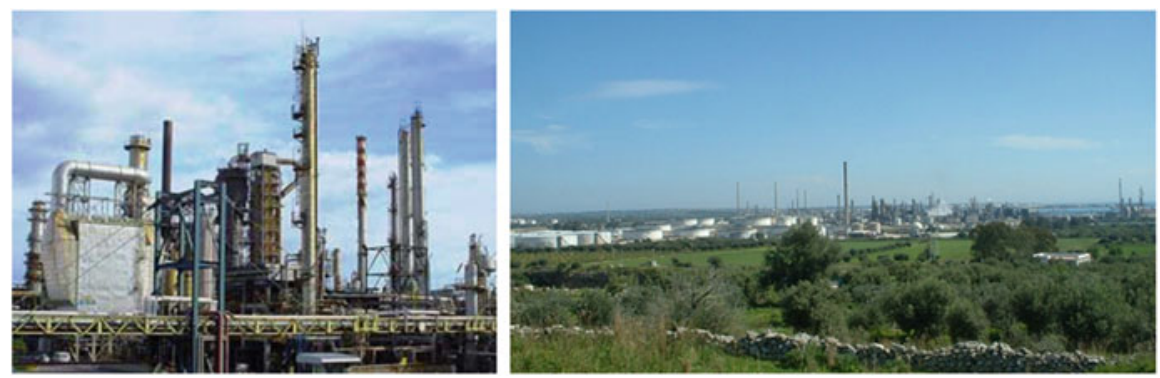

Fig. 14.28 The Italian petrochemical installations of Milazzo and Priolo (Sicily)

(Martelli 2012, 2013c), then, since the end of May 2012, for the civil structures too, thanks to the audits of the authors of this paper, as well as those of other GLIS members, which took place in the aforesaid commission in the framework of the "Survey on the State of Seismic Safety in Italy" of the Italian Chamber of Deputies in 2012 (Camera dei Deputati 2012a, b; Martelli 2013c; Martelli et al. 2013d; Martelli et al. 2013b).

In particular, the authors of this paper, on behalf of GLIS, have organized (or actively participated in) some conferences devoted to the promotion of schools safety (Martelli 2013a).

\subsubsection{Safety of the Italian Schools}

During the mentioned audits at the 8th Commission of the Italian Chamber of Deputies, held in the framework of the «Survey on the State of Seismic Safety in Italy», the very poor safety level of Italian schools was confirmed. In particular, it was stressed that $49 \%$ of school buildings in Italy has no certificate of use and occupancy (Martelli et al. 2013d). It was estimated that 27,920 Italian school buildings are located in highly seismic areas: 4,856 in Sicily, 4,608 in Campania, 3,130 (100\% of the total) in Calabria, 2,864 in Tuscany and 2,521 in Lazio. In addition, 6,122 schools are located in high landslide hazard areas: 994 in Campania, 815 in Emilia-Romagna and 629 in Lombardy (Martelli et al. 2013d).

Especially during the audits of the ENEA representatives (who were the first two authors of this paper) and of the President of the Italian Major Risks Commission, it was also pointed out that more than $70 \%$ of the Italian buildings are unable to withstand the earthquakes to which they may be subjected and that such a huge number of highly seismically vulnerable buildings includes several schools, often hosted by ancient or simply old constructions, for which seismic retrofit is impossible or overly expensive (Martelli et al. 2013d). In the above cases it is imperative to move the schools to other buildings, or existing (if they can ensure the necessary safety level or may be adequately seismically retrofitted), or ad hoc reconstructed with the best available technologies, by devoting the ancient buildings that cannot 

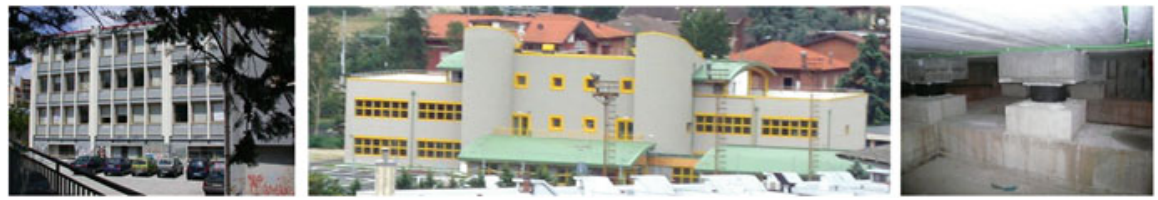

Fig. 14.29 Left: the Romita High School in Campobasso (Italy), in 2003 (when it hosted 1,300 students), before the demolition of its two most unsafe A and B blocks and reconstruction of block A with SI (see Fig. 14.18). At the centre and right: the new school of Marzabotto (Bologna, Italy, former seismic zone 3), which was seismically isolated (with the collaboration of ENEA) by means of 28 HDRBs and 14 SDs, with $500 \mathrm{~mm}$ diameters; it is the first seismically isolated school in Northern Italy, which was certified as safe by A. Martelli in September 2010
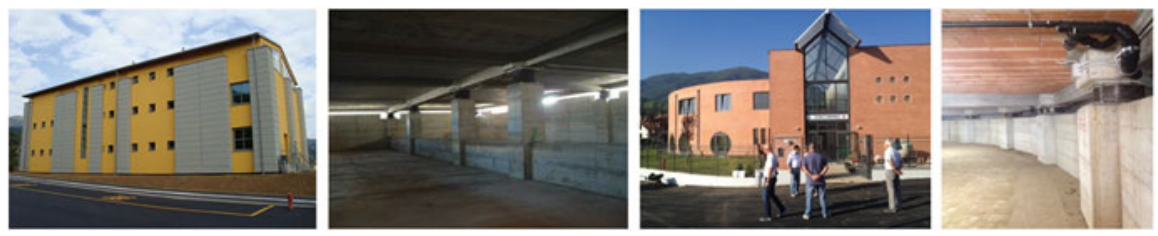

Fig. 14.30 Left: one of the 2 isolated blocks of the new primary and secondary school of Gallicano (Lucca, Italy), former seismic zone 2, which was erected with the collaboration of GLIS and was opened to activity in September 2009. Centre-left: some of the $46 \mathrm{HDRBs}$ installed in their underground floors. Centre-right: the new isolated kindergarten and primary school of Mulazzo (Massa Carrara, Italy), former seismic zone 2, certified as safe by A. Martelli and opened to activity in September 2012. Right: some of the 29 LRBs, which, together with 15 SDs, form its SI system

be adequately seismically retrofitted to other activities and by demolishing and rebuilding those which are just old (e.g. Figs. 14.18 and 14.29).

It is also essential to really complete the evaluations of seismic vulnerability of the Italian public buildings (including schools) within an extremely short time (according to the Decree of the President of the Council of Ministers Nr. 3274 of 2003, these evaluations should have been completed by the institutions in charge in a short time!).

With regard to the seismic protection of schools, as mentioned, the use of the AS systems (which have been developed and already significantly applied, even in Italy) ensures - in the case of SI - the absolute integrity of buildings and minimizes the panic effects, or - for example, in the case of ED systems - allows to approach to this objective (Martelli et al. 2013a, b, c). As mentioned in Sect. 14.2.5, such systems have already been used to protect a significant number of Italian schools, both of new construction and existing. In particular, after the first application of SI in the reconstruction of Francesco Jovine primary school in San Giuliano di Puglia, which ended and was certified as safe by A. Martelli in 2008 (Fig. 14.15), following the collapse of the previous one during the 2002 Molise \& Puglia earthquake (Fig. 14.14), the Italian schools protected with this technique, both of new construction and seismically retrofitted, are already at least 30, even in moderate 
seismic hazard areas (see, for example, Figs. 14.29 and 14.30 and Martelli et al. 2013a), and others are in progress.

SI is the technology that, nowadays, should be used for both the erection of all new schools in seismic areas and (where possible) seismic retrofit of the existing ones. For the latter, the applicability of SI obviously requires the presence or possibility of realization of structural gaps of sufficient width to enable the free transverse motion of the isolated superstructure (the related displacement can reach $40-50 \mathrm{~cm}$ in Italy and $1 \mathrm{~m}$ or even more in more seismic countries, as Japan and California).

Moreover, earthquakes are not the only accidental events to be hazardous for the safety of school occupants: others are, for example, fires and collapses due to static problems of school buildings and their parts. As a consequence of the tragic events of November 22, 2008, when Vito Scafidi, a young student, lost his life in the municipality of Rivoli (Torino), due to the collapse of the ceiling of his classroom of the Darwin High School, the Italian Civil Defence Department estimated the need for at least 13 billion Euros to put Italian schools in safe conditions. For the first time the amount of resources needed to address the long standing problem of unsafe schools conditions was assessed in Italy; it is a problem that, although "difficult to sustain" in the short term, should have represented a horizon within which to set the subsequent fiscal policies.

To raise public awareness and to stimulate the institutions to start in Italy, at last, adequate prevention policies for ensuring schools safety, GLIS organized, in collaboration with other partners, a meeting on "Safe schools: right and duty of a civil society", which was held in Asti on February 16, 2013 (Martelli et al. 2013d). The objective of this meeting, held on purpose just before the 2013 general elections of the new Italian Parliament, was to stress, to its future new members, the extreme urgency to secure the existing school buildings (the history of which is often very long and poorly documented) and the need to erect the new ones by adopting the most effective available technologies (in particular, with regard to earthquake protection, by extending the use of SI as much as possible - see Figs. 14.29 and 14.30). In fact, although the Italian Parliament has turned with these goals for some years, starting with a commitment act proposed by the first author of this paper and approved by the 8th Commission of the Chamber of Deputies and the government in 2009 , this act was not followed by any concrete measure (Martelli et al. 2013d).

Due to the mentioned extremely large percentage of Italian schools that are unsafe, a problem is obviously how to find the necessary funds, especially in the present very critical national economic situation. To face this problem, in April 2012, a bill had been submitted in the Italian Senate to give the opportunity to citizens to allocate 8 per thousand of their tax return to put school buildings in safe conditions (Martelli et al. 2013d). When it became clear, due to the anticipated end of the legislation, that this bill had no chance of being approved, it was turned into an amendment to the Stability Law, which, however, found a considerable resistance to its acceptance in the competent 5th Budget Commission of the Senate (Martelli et al. 2013d). Of no use was a resolution prepared with the collaboration of 
the first author of this paper and proposed in the 5th Commission on Budget, Treasury and Planning of the Chamber of Deputies at the beginning of December 2012, in support of the aforesaid proposals, although it had been signed by as many as 17 MPs from all parties (Martelli et al. 2013d). To help overcome these oppositions, GLIS and other partners wrote to both the representative of the government and the President of the 5th Commission of the Senate (Martelli et al. 2013d). Unfortunately, even these letters had no effect (no answer was received).

However, GLIS and its partners did not give up and have continued to stimulate the institutions, starting from the Asti meeting, where they formulated a request and a commitment: the request was addressed to the candidates of all parties in the general elections, who were invited to sign a statement of commitment to undertake the actions needed to ensure the safety of Italian schools (no electoral programs incorporated such actions within their priorities). The commitment, of the organizers, was to regularly check the implementation of such actions and to make the results of these verifications known, through Internet and by organizing special meetings: as mentioned by Martelli (2013a) and Martelli et al. (2013c, d), the first of such meetings were later held in Lanciano, Teramo, on April 19, 2013 and in Bologna on June 13 (the latter, which was organized with the collaboration of Rotary and Lions Clubs and other partners, was entitled "Safe schools: right and duty of a civil society", as in Asti).

During the aforesaid meetings it was stressed how, in spite of the shortage of economic resources, the active commitment of people of good will can result in a significant success. However, if the procedures are crippling, if the surveillance is uncoordinated and punitive rather than collaborative, if the main political and administrative choices on school safety were impromptu and irrational, even a great voluntary commitment of motivated and attentive people can produce only fragile results. In addition, it was complained that not always what appears from official documents and the certification of professionals and technicians corresponds to reality. Sometimes, modification and renovation works carried out on existing buildings are conducted in a superficial and irresponsible way. What is more serious is that there are people who are aware of poorly made and dangerous works, but do not denounce this.

With regard to the problem of economic resources, it was agreed that the proposed use of the part of the 8 per thousand of the tax revenues allocated to the state can be only an emergency and temporary solution: a comprehensive plan of budget allocation, dedicated in a structured and consistent way, is needed. Problems like school safety cannot be solved thanks to emergency procedures, which did so much harm to Italy in recent times: the rules must always apply, even if they have to be simplified, and the principle of responsibility shall apply.

As to the issue of information and the danger of generating alarm through it, participants in the Asti meeting claimed the right of the public opinion to be made aware of all, in time to pick and choose, rather than somebody still risks to die unexpectedly under a pile of rubble. The role of a full and transparent information, according to the Japanese experience, was reminded, together with the use that the 
population can make of this information through appropriate aggregations to increase safety of schools. For example, a case reported was that of a school on which a sign was posted which declared that the building had not been erected according to anti-seismic norms: in this way, people can choose, deciding whether to drop out of school, or pressure the administration to force it to put the building in safe conditions. The filtered information under the pretext of the danger of creating alarmism allows opacity and arbitrary decisions, especially in a corrupt country, and is a betrayal of democracy, which must not only be a proxy.

Risk evaluation and selection of priorities was a further issue that was discussed in all aforesaid meetings. There are not only the schools, not only earthquakes: there are also the hydro-geological events, floods and many other disasters. In case of limited overall economic resources, like those existing in Italy, a choice of priorities is a must. However, this choice has many reasons, including the sensitivity of the population to give consent to the choice itself. The frequent accidents and the fact that schools host our children are reasons to arouse such a sensitivity. Furthermore, as to earthquakes, the recent developments in the seismological field (such as the so-called "earthquake prediction experiments", or, more precisely, "intermediateterm middle-range earthquake predictions"), if duly considered, can be very useful for defining the intervention priorities (Martelli et al. 2013a). Finally, we remind that repair of the damage caused by an earthquake costs from three to five times the funds needed for preventive measures aimed at ensuring the safety of structures (Martelli et al. 2013d).

Luckily, it seems that now, at last, the issue of protecting the Italian schools, by devoting sufficient funds to this purpose, has been understood by some qualified representatives of the Italian institutions and political parties. We hope that adequate actions will be really urgently undertaken.

\subsubsection{Safety of Italian Hospitals and Cultural Heritage}

Contrary to schools, only a limited number of Italian hospitals has already been protected by SI. For schools, it was necessary to wait for the collapse of that mentioned above in San Giuliano di Puglia in 2002, before deciding to use the aforesaid technique. For a wide application of SI to the Italian hospitals too, shall we need to wait that a next earthquake destroys one of them and causes further victims? Have we learned nothing from the damages suffered by the hospital in Mormanno (Martelli 2014), knocked out by the modest Pollino event, on October 26,2012 , of moment magnitude $\mathrm{M}_{\mathrm{W}}=5.2$ ? If the earthquake had been (or will be) more violent (as is very possible in that area), what would have happened (or what will happen)?

Moreover, as far as the protection of cultural heritage is concerned, we must unfortunately note that no Italian museums, even of new construction, have been so far protected by SI. There are only a few masterpieces that have been seismically isolated so far (Bronzes of Riace, etc. - see, for instance, Martelli 2009). However, 
this will be insufficient to protect them from the collapse of the museum (or parts of it, e.g. the roof), if it is unable to withstand the possible earthquakes. Have we learned nothing from the collapse of several statues in the museum of L'Aquila during the 2009 Abruzzo earthquake?

Finally, is the collapse of so many valuable monumental buildings during quakes acceptable, as occurred during the aforesaid Abruzzo event? As mentioned in Sect. 14.2.5, new retrofit techniques using SI in a sub-foundation (namely applicable to monumental buildings, because they are compatible with the conservation requirements) have been developed in Italy (Clemente et al. 2011) and attempts to use them in Abruzzo, for the reconstruction (Salvatori 2013) or as prevention measures, are in progress (Fig. 14.25). However, let's hope that will be really adopted.

\subsubsection{Safety of High Risk (HR) Chemical Plants and General Remarks on Seismic Prevention}

It is historically proven that a large part of the Italian territory is characterized by high or least significant seismic hazard (up to magnitude values of at least $\mathrm{M}=7.0$ 7.5); in addition, some areas are also exposed to possible non-negligible tsunamis in case of earthquakes with epicentres in the sea (even in shallow water zones) or near it, on the coast. Nevertheless, in Italy, there are now more than 1,000 HR industrial installations subjected to the requirements of the so-called "Seveso II" decree, namely in which there are potentially dangerous substances in quantities that exceed certain thresholds. Many of these installations are also subjected to the so-called "Integrated Environmental Authorization" (AIA). Some of them are located in areas of high seismic hazard, such as, for instance, in Sicily, in those of Milazzo and Priolo-Gargallo (Fig. 14.28). It is worthwhile remembering that, in 1693, the plain of Catania, which includes the Priolo-Gargallo site, was hit by one of the most devastating earthquakes occurred in Italy, probably more violent than that of Messina \& Reggio Calabria of $1908(\mathrm{M}=7.2)$, and that (as later in 1908) such an earthquake generated a violent tsunami. It shall also be remembered that Milazzo is located in the Messina Province and that Mount Marsili, a huge submerged volcano (the biggest in Europe, $70 \mathrm{~km}$ long, $30 \mathrm{~km}$ wide and 3,000 m high), rises in front of it, in the Tyrrhenian Sea, with a crater at $450 \mathrm{~m}$ from the water surface: according to some geologists, this volcano might explode at any time, with the possible collapse of a large part of its flanks, by causing a violent tsunami.

In the Priolo-Gargallo and Milazzo sites, should the HR plants that are present there be inadequately protected from earthquakes, an event of $\mathrm{M} \approx 7.0$ (which is quite possible) would trigger serious accidents, perhaps even worse than those occurred in Turkey due to the Kocaeli earthquake of August 17, 1999 (Fig. 14.27), with serious consequences for the population and the environment, 
besides the economic ones. Moreover, if the earthquake were followed by a significant tsunami, the proximity of such plants to the coast, in the absence of barriers with adequate strength and height (which is the present situation), would make these consequences even more dramatic.

As reported by some scientific publications for several years and, more recently (after the 2011 Tohoku earthquake and tsunami), even by the press, in Italy, in spite of the availability of maps covering both the seismic hazard and that related to tsunamis for several years, there are still no organic nor adequate legal rules for chemical installations, even for the HR ones (contrary to what happens for civil constructions on the one hand and for nuclear installations on the other), regarding their seismic design, the measures to be taken to protect them (when necessary) from tsunamis and those to make the existing plants resistant to both earthquakes and tsunamis. About the inadequacy of the rules currently in use in Italy for the HR chemical plants, we note that such plants are now designed taking, as seismic loads, those defined by the national codes, which are based essentially on the characteristics of civil buildings, namely on a probabilistic approach (Probabilistic Seismic Hazard Assessment or PSHA). According to some well-known seismologists (in Italy, in particular, the team led by the GLIS and ASSISi honorary member Prof. Giuliano Panza of the University of Trieste and the International Center of Theoretical Physics), these seismic loads can, therefore, be particularly inappropriate for constructions that are certainly much more complex (in terms of structures, systems and components) than the civil ones. The reasons for this are both that the seismic risk of the HR installations is significantly larger than that concerning the civil constructions and that the PSHA approach showed severe limits on the occasion of the most violent earthquakes recently occurred in the world (Martelli et al. 2013a, b, c): therefore, according to the aforesaid experts, the use of the PSHA approach should be combined with that of a deterministic one (e.g. the so called Neo-Deterministic Seismic Hazard Assessment or NDSHA), which, differently from the PSHA, is based on the physics of the phenomena involved and is proving to be more and more reliable and able to quickly adapt to the advancements of the seismological research (Martelli 2013c; Martelli et al. 2013a, b, c).

Moreover, the information available about the level of protection from earthquakes and tsunamis that characterizes the existing HR plants in Italy is still far from exhaustive, and indeed, as it has been reported by some publications for some time, there is a clear evidence of the high vulnerability (at least at the time of these publications) of HR plants and tanks that are located in areas characterized by high seismic and tsunami hazards in Italy (Martelli 2012, 2013c; Clemente and Martelli 2013).

As the first author of the paper denounced in 2012 (Martelli 2012), the warnings that he had already launched in 2011 and his suggestions remained fully ignored; similar subsequent warnings of ENEA, in particular at some important events devoted to the lessons of Tohoku earthquake, were also unsuccessful (Martelli 2013c). Anyway, this had occurred even earlier, although GLIS and ENEA had tried to bring the problem of seismic safety of the HR chemical plants and 
components to the attention of the institutions, media and public opinion (Martelli 2012, 2013c).

The above inattention ceased only because of the concerns on the high seismic risk of the Sicilian HR chemical plants that were stressed at the conference on "Lessons of the Tohoku earthquake", held at the ENEA headquarters in Rome on July 1st, 2011 and, especially, as a consequence of a parliamentary question, based on a proposal of GLIS, that was submitted by the president of the 8th Commission of the Chamber of Deputies on September 8, 2011, with the above-mentioned contents (Alessandri 2011; Martelli 2012, 2013c). Thanks to this question and to a meeting held in Milazzo on December 2, 2011, at last, the subject began to attract a considerable interest of media and public opinion (Martelli 2012, 2013c). Unfortunately, however, not that of the national and regional institutions, even after the serious concerns expressed and communicated to Major Risks Commission by the seismologists of University of Trieste and other well-known experts of the Russian Academy of Sciences in early January 2012, based on the results of their "earthquake prediction experiments", about the possible occurrence, in the intermediate term, of a violent earthquake in Southern Italy, in particular (according to the Russian experts) in an area including Southern Calabria and Eastern Sicily (however, in a large area, certainly not in a precise location - see Martelli 2012, 2013c; Martelli et al. 2013b, c). Therefore, on January 31, 2012, the aforesaid parliamentary question was transformed into a resolution (Alessandri 2012; Martelli 2012, 2013c; Martelli et al. 2013b, c). In addition, the issue of seismic protection of HR chemical plants was part of those examined in the "Survey on the State of Seismic Safety in Italy" held at the Italian Chamber of Deputies in 2012 (Benamati 2012; Martelli 2013c).

Despite further scientific events and information on the seismic safety of the HR chemical plants held, in particular, in Sicily (at Augusta and Messina, in February and March 2012, respectively - see Martelli 2013c) and the proliferation of newspaper articles and radio and TV reportages (especially after the beginning of the seismic events in Emilia in May 2012 and the disclosure of the fact that, at the beginning of March 2012, the seismologists of the University of Trieste had expressed their concerns for Northern Italy too - see Martelli 2012, 2013c), the Italian institutions have continued to remain idle. In the meantime, very little has been done in terms of prevention, at least to limit the severe consequences that a violent earthquake (whether or not followed by a tsunami) could have if it hits the Sicilian areas of Milazzo or Priolo; instead, many sterile and damaging controversies were made.

The aforesaid controversies, born following statements of the first author of this paper especially after the 2012 Emilia earthquake, misrepresented the positions he had expressed about the "earthquake prediction experiments" and about the concerns communicated by the aforementioned well known seismologists for Southern Italy too (Martelli 2013c). This unnecessarily and detrimentally exacerbated the climate, by also leading to panic situations and diverting the attention from the main goal: to urgently undertake a serious prevention policy, as regards both civil and industrial constructions, especially (but not only) in Southern Italy. The information 
available to date tells us that earthquakes can be predicted with high statistical significance, but with great spatial and temporal uncertainties and with the possibility of false alarms (Panza et al. 2011; Martelli et al. 2013a). The information should, therefore, be used in an appropriate manner, to take urgent preventive actions that will be essential if a strong earthquake will actually occur, but that will be useful in case of false alarm too, i.e. if the strong earthquake will not occur (such actions concern, for example, the verification and, if needed, putting in safe conditions of facilities characterized by a particular risk, the preparation of the civil protection system, information to the public opinion, etc.).

As a matter of fact, the ENEA experts limited themselves to apply their knowledge in the field of earthquake engineering in order to assess the risk concerning the HR chemical plants, which are characterized by a very high exposure and, as mentioned, a seismic vulnerability that is very often at least unknown. Obviously, to express this judgment, they could not neglect the concerns and the results of the cited "earthquake prediction experiments". In disclosing the results of such evaluations, covering Southern Italy, the only goal of ENEA was, as always, to encourage the institutions to establish the necessary measures, within their competences, and to give, as far as possible, the necessary information to the public opinion.

In the information and stimulus work that ENEA had carried out, very unheeded, for a long time (not for a few days, as can be easily checked), unfortunately, often happened that the statements of its experts were distorted, unfortunately not only by media: this, however, was a risk that had to be be taken, because silence would have been even worse. On the other hand, what ENEA and the authors of this paper actually said and are saying is certified, for example, by several TV and radio reportages transmitted since April 10, 2012 (i.e. well before the 2012 Emilia earthquake - see Clemente and Martelli 2013).

The fear that earthquake has aroused in the public opinion in Southern Italy (first when there was one in progress in the north of the country, then when, on October 26, 2012, the Pollino area was hit in Calabria, namely really in the south, by a $\mathrm{M}=5.0$ event, and more recently due to some events which are going on hitting both Southern and Central Italy) takes origin from the fact that, only now, having proof the problem, many are realizing how unsafe their homes, the schools where their children study and the places they go to can be, and that only now many are waking up to reality, becoming aware of the serious deficiencies that plague Italy in the field of the prevention of seismic risk. Creating panic shall be certainly avoided, but we must not also pass over the problem and we shall aim at transforming this fear into "claim for prevention": this is not an impossible goal, although, of course, the path is full of traps (Martelli 2013c).

The safety of HR chemical plants was discussed in detail at the conference on «Seismic safety of chemical high risk plants», jointly organized by ENEA and GLIS, which was held with great success in Rome on February 7, 2013 (Clemente and Martelli 2013; Martelli 2013c). This conference brought together representatives of all the institutions involved in the topics discussed. Despite the difficult political moment, it was considered appropriate that the event should take place before the Italian general elections of 2013, because of the importance of the issues 

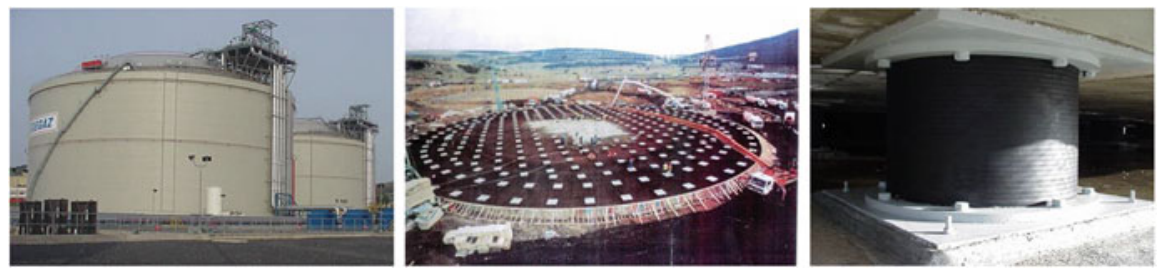

Fig. 14.31 Left: one of the two LNG tanks of Egegaz in Aliaga (Turkey), which were seismically isolated using 112 LRBs and 241 LDRBs. At the centre: view of the isolators during construction. Right: an installed LRB
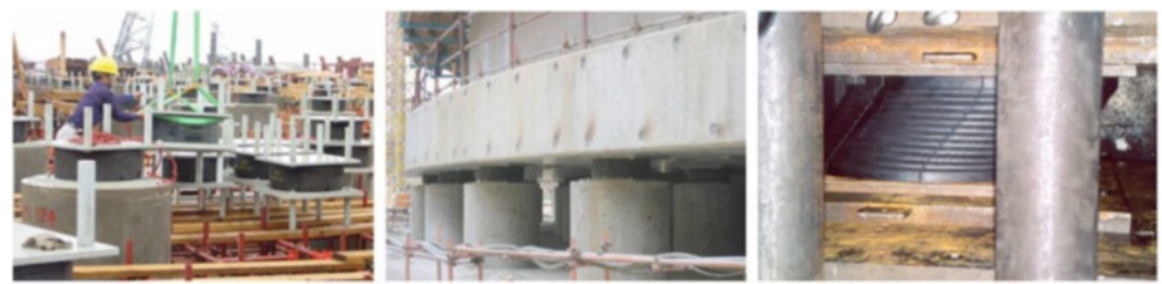

Fig. 14.32 Left: one of the two seismically isolated LNG tanks in the Guandong Province (Southern China) during construction (each of them was isolated by means of 360 HDRBs). At the centre: some of the isolators after their installation. Right: a HDRB during acceptance tests

dealt with in it and also to stimulate the subsequent (namely, the present) government to address these issues with the necessary urgency.

At the 2013 Rome conference, it was agreed on the need and urgency to:

- adequately address the problem of seismic safety and in the face of a possible tsunami of Italian HR chemical plants and components, especially of the petrochemical installations of Priolo-Gargallo and Milazzo;

- proceed with urgency to the development of specific regulations for earthquakeresistant and anti-tsunami designs of such plants and components and, where necessary, for the retrofit of the existing ones;

- build, at least in areas of high seismic hazard, especially the LNG tanks, but also other types of HR chemical installations and components of new construction, by making an extensive use of AS systems, in particular (where possible) of SI;

- accurately assess, in the areas of significant seismic and/or tsunami hazard, the vulnerability of these HR plants and components that are already existing;

- retrofit such plants and components using, to protect them from earthquakes (where useful and possible), SI or ED systems (which, unfortunately, are very little applied in Italy in this field, contrary to other countries, as shown by Clemente and Martelli 2013; Martelli et al. 2013a, and Figs. 14.31 and 14.32); 
- proceed to the identification of the situations of highest seismic or tsunami risk, for the existing HR chemical installations, so as to make the civil defence system capable of adequately addressing possible accidents caused by the collapse or damage of the plants or components present in such installations;

- start in Italy too, at last, a correct program of participated information of the population and rise the perception of seismic risk in it.

We are confident that the loud and at last unanimous message of the Italian scientific and technological community that came out of the Rome conference, has really allowed to overcome the harmful and useless controversies of 2012 (Clemente and Martelli 2013; Martelli 2013c) and is now able to stimulate the present and future Italian governments to tackle the aforesaid serious problems with the indispensable urgency, with the contribution of all the competences necessary to that purpose.

\subsection{Costs of Seismic Isolation}

As mentioned, SI is a technology of great interest not only for public or strategic buildings, but also for the residential ones. Indeed, in addition to confer a level of seismic safety much higher than that obtainable with conventional foundations and to allow to avoid the costs (of repair, demolition, reconstruction, relocation, etc.) that, after a significant earthquake, should be faced for the structures with conventional foundations, the use of SI entails, for new buildings, a very limited additional construction cost in Italy. In countries as Italy, were the seismic code allows to somewhat decrease the seismic loads acting on the structures, if they are protected by SI (Sect. 14.5), the aforesaid cost decreases with increasing seismic hazard of the area where the building is located, number of its floors and extent of its structural asymmetries.

Typically (as occurred, for example, for the 5 isolated building of the new San Samuele residential district in Cerignola, Foggia, which was certified as safe by the first author of this paper - see Martelli and Forni 2010), this additional construction cost vanishes in Italy for residential buildings of 5 floors, even if they are very regular, which are located in areas of medium seismicity (i.e. former Italian seismic zone 2). As a second example, for the new school of Marzabotto (opened to activity in 2010, again with safety certification of the first authors of this paper, see Fig. 14.29), even though it arose in an area considered to be of low seismicity (former Italian seismic zone 3) and despite its limited height and non-use of the underground floor where the isolators have been installed (which is considered as a "technical space"), the additional cost due to SI was of only 96,000 Euros, out of a total construction building cost of about five million Euros (Basu et al. 2014).

Moreover, for interventions on the existing buildings, the use of SI could even cause a saving, as demonstrated, for example, by the case of a dwelling building of Fabriano, Ancona, damaged by the 1997-1998 Marche and Umbria earthquake, 
which was also certified as safe by the first author of this paper in 2006 (Martelli and Forni 2011a): in fact, it is not necessary to "undress" the structure, so as to be able to stiffen beams and nodes, or to insert shear walls (which is often quite complicated).

Finally, if the intervention is carried out as a preventive measure (that is, before the building is damaged by an earthquake), it is often possible to keep the building in use (except, of course, for the storey at which the isolators have to be inserted and, to this end, pillars and/or load-bearing walls have to be cut and, if necessary, strengthened): this advantage is of particular importance for the retrofit of hospitals (Martelli 2014).

\subsection{Remarks on the Correct Use of Anti-seismic Systems and Devices}

The large effects of earthquake lessons and seismic design code features on the extent of the use of the AS systems in the various countries shall be stressed (Martelli 2010; Martelli and Forni 2010, 2011a, b). In the codes of countries like Japan, the USA and Chile SI is considered as a safety measure additional to the conventional design; consequently, the use of SI obviously always introduces additional construction costs. Nevertheless, this technique is being widely adopted by the Japanese, due to their high level of perception of the seismic risk and because violent earthquakes are very frequent in their country (Martelli et al. 2011, 2012a).

The aforesaid level of perception is much lower elsewhere: this is the reason why, to limit or even sometimes balance the additional construction costs entailed by the use of SI (and, thus, to promote a significant application of this technique), the seismic codes of other countries (Italy, P.R. China, Armenia, etc.) allow for some lowering of the seismic forces acting on the superstructure when SI is used (Clemente and Buffarini 2010). Thus, in these countries, a real safety will be ensured to the isolated structures if and only if great care is paid to:

- the selection of the SI devices (taking into account the amplitude of vertical motion and low frequency vibrations), their qualification, production quality, installation, protection, maintenance and verification that their design features remain unchanged during the entire structure life;

- some further construction details (structural gaps, their protections, interface elements - e.g. gas and other safety-related pipes, cables, stairs, lifts -, etc.).

Otherwise, the isolators, instead of largely enhancing the seismic protection, will make the structure less earthquake resistant with respect to a conventionally founded one and, thus, will expose both human life and the entire SI technology to great risks.

Last but not least, a common key requirement for the optimal performance of all kinds of AS systems and devices (but especially of the isolators) is the realistic and reliable definition of seismic input (Martelli 2010; Martelli and Forni 2010; 
Martelli et al. 2011; Panza et al. 2011), which cannot rely only upon the oversimplified routine probabilistic methods, mainly when dealing with displacements definition (on which the design of isolated structures is based): thus, the ongoing rapid extension of the use of the AS systems and devices requires a considerable improvement of the PSHA approach, which is now in use in several countries (including Italy). Taking into account the mentioned unreliable results shown by PSHA for several violent earthquakes in the last decade (Martelli and Forni 2011b; Martelli and Forni 2011; Panza et al. 2011), such a change is very urgent now and can be achieved by complementing PSHA through the development and application of deterministic models, e.g. NDSHA. This particularly applies to the P.R. China, Italy, New Zealand and Japan, to ensure a safe reconstruction after the earthquakes of Wenchuan (2008), Abruzzo (2009), Canterbury and Christchurch (2010 and 2011) and Tohoku (2011), because SI is widely used in the concerned areas.

All said items were discussed in Italy by the 8th Commission on Environment, Territory and Public Works of the Italian Chamber of Deputies in 2010 and 2011, based on two proposals drafted by the first author of this paper, with the collaboration of other experts (Martelli et al. 2011, 2012a). Following these discussion and audits of various experts (including those of the first, second, third and fifth authors of this paper), one of such resolutions (that most detailed), was approved, with minor changes, by the aforesaid commission and by the Italian Government on June 8, 2011 (Martelli et al. 2011). The final document (Benamati et al. 2011), after some introductory remarks, contains recommendations for modifications of some parts of the existing Italian and European seismic codes that concern the AS systems and devices and the structures provided with them (experimental qualification of the new device types to be carried out on prototypes by subjecting them to at least bi-directional excitations, control of all construction phases to be performed by an expert in the field, recommendations and requirements to be provided by him in his final certificate concerning the structural safety of the structure, etc.), as well as the need for using the NDSHA together with the PSHA for the definition of seismic input (in particular for that of the design displacement, which is a key parameter for the design of isolated structures). These recommendations have been reported in detail by Martelli et al. (2011). Based on them and on the results of the "Survey on the State of Seismic Safety in Italy" (Benamati 2012), promoted with the collaboration of the first author of this paper and held at the 8th Commission on Environment, Territory and Public Works of the Italian Chamber of Deputies in 2012 (with, as mentioned, audits of the authors of this paper and other GLIS and ASSISi members), a new law concerning modifications of the Italian seismic code was proposed during the last legislation and was recently proposed again (Martelli et al. 2013c). 


\subsection{Conclusive Remarks}

SI and the other AS systems have already been widely used in over 30 countries and their application is increasing more and more, for both new constructions and retrofits, for all kinds of structures and their materials. The features of the design rules used, as well as earthquake lessons, have plaid a key role for the success of the aforesaid technologies. Japan is the leading country for the number of applications of both SI and ED systems. For the overall number of applications, it is now followed by the P.R. China, the Russian Federation, the USA and Italy. Italy (where the contributions provided by ENEA and GLIS have been of fundamental importance) is the leading country at European level, with regard to both SI and ED of buildings, bridges and viaducts. In addition, it is a worldwide leading country for the use of AS systems and devices to protect cultural heritage (Martelli 2009; Martelli and Forni 2010). Its applications are being significantly extended after the 2009 Abruzzo earthquake. Italian passive AS devices have been installed in several other countries too.

SI is now worldwide recognized as particularly beneficial for the protection of strategic constructions like civil defence centres and hospitals (by ensuring their full integrity and operability after the earthquake) and for schools and other highly populated public buildings (also because the large values of the isolated superstructure vibration periods minimize panic). Some codes (e.g. those adopted in Italy, P.R. China, Armenia, etc.) allow for taking advantage of the reduction of seismic forces operated by SI: their use makes SI attractive for the dwelling buildings too, because the additional construction costs due to the use of this technique (if any) are frequently rather limited.

In order to really strongly enhance the seismic protection of our communities, an extensive but correct application of the AS systems is necessary (Martelli and Forni 2011b; Martelli et al. 2011, 2012a, 2013b, c). With regard to Italy, a wide-ranging use of such systems (where possible of SI) will certainly greatly contribute to enhance the seismic safety of structures, since there over $70 \%$ of those existing are not able to withstand the earthquakes which may hit them and since this number includes many schools, other strategic or public buildings and important HR chemical plants. This is particularly necessary and urgent for schools, which (together with hospitals) are the buildings that should guarantee the highest safety level, and for the HR chemical plants, which are characterized by a very high exposure. To contribute to promote risk prevention policies, in particular for the seismic one and for schools, the National Coordination of Voluntary Associations for Seismic and Environmental Prevention (Coordinamento Nazionale Associazioni di Volontariato per la Prevenzione Sismica e Ambientale - Co. Prev.) was founded at the Bologna meeting of June 13, 2013, which was organized by the first author of this paper (who is member of the Co.Prev. Technical Committee - see Martelli et al. 2013c, and Martelli 2014).

To achieve the objective of widely extend the correct use of the AS systems, regulatory and legislative measures, such as those that were proposed in Italy by the 
8th Commission on the Environment, Territory and Public Works of the Chamber of Deputies for the isolated structures in general and for protecting the high risk chemical plants in particular, may considerably contribute, especially in the countries (like Italy) where the perception of seismic risk is not yet sufficient. In fact, the use of AS systems (in particular that of SI) will hopefully strongly increase not only for the protection of civil structures, but also for that of cultural heritage and high risk plants (Martelli and Forni 2010; Martelli et al. 2013b, c). For the application of the AS systems to monumental buildings, the problem is the compatibility with the conservation requirements (Martelli 2009). For that to the high risk plants, SI has a great potential not only for nuclear structures, but also for chemical components like LNG tanks, for which, to date, only a limited number of applications exists or has been planned (in South Korea, P.R. China, Turkey, France, Greece, Mexico, Chile and Peru): in fact, detailed studies have shown that SI is indispensable for such components in highly seismic areas (Dolce et al. 2006; Martelli et al. 2011, 2013b, c; JSSI 2013).

Thus, as recommended by a parliamentary question of the President of the 8th Commission of the Italian Chamber of Deputies in September 2011 (Alessandri 2011), which was fully reported by Martelli and Forni (2011a), and by a resolution which was proposed by the same member of the Italian Parliament at the end of January 2012 (Alessandri 2012), we hope that the use of SI will soon increase for high risk chemical installations in Italy. This applies, especially, to Sicily, in sites like those of Milazzo (not far from the area destroyed by the 1908 Messina \& Reggio Calabria earthquake and tsunami, besides being in front of the submerged Marsili Volcano) and Priolo (located in the Catania Plane, which was razed by the 1,693 event): in both sites hundreds of quite seismically vulnerable cylindrical and spherical tanks already exist (only 3 retrofitted using SI, to date, see Fig. 14.16) and, in the latter, the construction of a large re-gasification terminal with LNG tanks had been planned.

Generally speaking, however, it shall be kept in mind that the use of SI in countries as Italy, where the designers are allowed by the code to decrease the seismic forces acting on the superstructure when adopting this technology, requires:

- first of all, a reliable definition of the seismic input, namely by means of intensive use of NDSHA, as well, in addition to PSHA;

- then a very careful selection, design, manufacturing, installation, protection and maintenance of the SI devices during the entire life of the isolated structure;

- finally, particular attention to be also paid to some further construction aspects (in particular, to the design, realization, protection and maintenance of the structural gaps and the safety-related pipelines - e.g. the gas ones -, again during the entire life of the isolated structure).

Otherwise, the seismic safety of these structures would be lower than that of the conventionally founded ones.

In any case, the technologies to make buildings safe during earthquakes, in Italy and elsewhere, exist and it is foolish not to use them extensively. Certainly the goal is (at least theoretically) easier for new construction, while the difficulties to be 
overcome in order to make the existing buildings safe are frequently huge, from an economic standpoint. However, this does not justify the continuing inertia of the institutions, in Italy and in other countries.

In Italy it will take several decades to solve the problem of the high seismic risk of the existing buildings, but to do this we must start immediately, acting by priority and using the best available technologies as described above. If we want public opinion to acquire a correct perception of risks (in particular of the seismic one), the institutions shall set an example, by promoting, at last, proper prevention policies (Martelli et al. 2013b).

Open Access This chapter is distributed under the terms of the Creative Commons Attribution Noncommercial License, which permits any noncommercial use, distribution, and reproduction in any medium, provided the original author(s) and source are credited.

\section{References}

Alessandri A (2011) Parliamentary question requiring written answers no. 4-1360 (concerning the seismic protection of high risk chemical plants). In: Atti Parlamentari - Camera dei Deputati (Parliamentary Acts - Italian Chamber of Deputies), Rome, Italy, pp 24010-24013 (in Italian)

Alessandri A (2012) Resolution in the VIII Commission of the Chamber of Deputies no. 7-00764 (concerning the seismic protection of high risk chemical plants). In: Atti Parlamentari Camera dei Deputati (Parliamentary Acts - Italian Chamber of Deputies), Rome, Italy, pp 27324-27327 (in Italian)

Basu B, Bursi OS, Casciati F, Casciati S, Del Grosso A, Domaneschi M, Faravelli L, Holnicki J, Irschik H, Krommer M, Lepidi M, Martelli A, Ozturk B, Pozo F, Pujol G, Rakicevic Z, Rodellar J (2014) An EACS joint perspective. Recent studies in civil structural control across Europe. Struct Control Health Monit. doi:10.1002/stc

Benamati G (proponent and rapporteur) (2012) Indagine conoscitiva sullo stato della sicurezza sismica in Italia - Programma. In: Resoconti delle Giunte e Commissioni - Resoconto dell'VIII Commissione Permanente (Ambiente, Territorio e Lavori Pubblici), Italian Chamber of Deputies, Rome, Italy, 12 Apr, pp 64-67 (in Italian)

Benamati G, Ginoble T, Alessandri A (2011) 7-00414 Benamati: In materia di isolamento sismico delle costruzioni civili e industriali (7-00414 Benamati: on seismic isolation of civil and industrial structures). Resolution approved by the VIII Commission no. 8/00124, 16th Legislature, Announcement Meeting of June 8, 2011. In: Bollettino della Camera dei Deputati (Bulletin of the Italian Chamber of Deputies), Rome, Italy 491(5):388-393 (in Italian)

Camera dei Deputati (ed) (2012a) Indagine conoscitiva sullo stato della sicurezza sismica in Italia - Audizione di rappresentanti dell'ENEA, del professor Giuliano Panza e del professor Antonello Salvatori. In: Resoconti Stenografici delle Indagini Conoscitive - Commissione VIII, Seduta di Mercoledì 30 Maggio 2012, Italian Chamber of Deputies, Rome, Italy, pp 3-22 (in Italian)

Camera dei Deputati (ed) (2012b) Indagine conoscitiva sullo stato della sicurezza sismica in Italia - Audizione di rappresentanti dell'ENEA. In: Resoconti Stenografici delle Indagini Conoscitive - Commissione VIII, Seduta di Giovedì 13 Settembre 2012, Italian Chamber of Deputies, Rome, Italy, pp 2-27 (in Italian)

Clemente P and Buffarini G (2010) Base isolation: design and optimization criteria. In: Seismic Isolation And Protection Systems (SIAPS), Mathematical Sciences Publishers (MSP), Berkeley, CA, USA 1(1):17-40. doi:10.2140/siaps.2010.1.17 
Clemente P, Martelli A (eds) (2013) Atti della Giornata di Studio Sicurezza Sismica degli Impianti Chimici a Rischio di Incidente Rilevante, ENEA Report, ISBN 978-88-8286-285-5, Rome, Italy (in Italian)

Clemente P, De Stefano A, Renna S (2011) Application of seismic isolation in the retrofit of historical buildings. In: 12th World conference on seismic isolation, energy dissipation and active vibration control of structures (12WCSI), proceedings on CD, ASSISi, Sochi/Russian Federation/Moskow, 20-23 Sept 2011

Dolce M, Martelli A, Panza G (2006) Moderni Metodi di Protezione dagli Effetti dei Terremoti. In: Martelli A (ed) Special edition for the Italian Civil Defence Department, Milan: $21 \mathrm{mo}$ Secolo (in Italian)

Eisenberg J et al. (eds) (2011) 12th World conference on seismic isolation, energy dissipation and active vibration control of structures - conference proceedings and abstract book (CD), ASSISi, Sochi/Russian Federation/Moskow, 20-23 Sept 2011

JSSI (ed) (2013) Seismic isolation, energy dissipation and active vibration control of structures, proceedings on electronic key of the ASSISi 13th World conference (13WCSI) \& JSSI 20th Anniversary International Symposium, JSSI, Sendai, Japan/Tokyo, 24-26 Sept 2013

Kani N (2008) Current state of seismic-isolation design. In: Proceedings of the 14th World conference on earthquake engineering, Beijing, 12-17 Oct 2008

Martelli A (2009) Development and application of innovative anti-seismic systems for the seismic protection of cultural heritage. Key-note lecture. In: Mazzolani FM (ed) Protection of historical buildings; Proceeding of the PROHITECH 2009 international conference, CRC Press - Taylor and Francis Group 1, Rome, Italy/Leiden, pp 43-52, 22-24 June 2009

Martelli A (2010) On the need for a reliable seismic input assessment for optimized design and retrofit of seismically isolated civil and industrial structures, equipment and cultural heritage. Pure Appl Geophys. doi:10.1007/s00024-010-0120-2

Martelli A (2012) Impianti chimici RIR italiani: le incognite terremoto e maremoto. In: Il Giornale dell'Ingegnere, Focus. Milan, Italy 7, pp 8-11 (in Italian)

Martelli A (2013a) Prosegue l'impegno del GLIS per la prevenzione sismica - Anzitutto si proteggano finalmente le scuole italiane. In: 21 mo Secolo - Scienza e Tecnologia. Milan, Italy $2 / 2013$, pp 17-23 (in Italian)

Martelli A (2013b) L'ASSISi 13th World Conference di Sendai (Giappone) e le più recenti e prossime manifestazioni del GLIS - Continua a crescere l'applicazione dei sistemi antisismici. In: 21mo Secolo - Scienza e Tecnologia, Milan, Italy 3/2013, pp 19-26

Martelli A (2013c) Impianti chimici a rischio terremoto: proteggerli si può, basta volerlo. In: 2087, Fabbriche a Rischio e Terremoti, Rome, Italy 3, pp 4-10 (in Italian)

Martelli A (2014) Scuole ed ospedali: edifici che "dovrebbero" restare totalmente integri e pienamente operativi dopo un terremoto. Come garantirlo, In: La Proprietà Edilizia 2 (in press, in Italian).

Martelli A, Forni M (2010) Seismic isolation and other anti-seismic systems: recent applications in Italy and worldwide. In: Seismic Isolation And Protection Systems (SIAPS), Mathematical Sciences Publishers (MSP), Berkeley, CA, USA 1(1):75-123. doi:10.2140/siaps.2010.1.75

Martelli A, Forni M (2011a) Seismic retrofit of existing buildings by means of seismic isolation: some remarks on the Italian experience and the new projects. Invited paper. In: Minisymposium on Innovative vs Conventional Retrofitting of Existing Buildings, 3rd International Conference on Computational Methods in Structural Dynamics and Earthquake Engineering (COMPDYN 2011), Corfu, 26-28 May 2011

Martelli A, Forni M (2011b) Recent worldwide application of seismic isolation and energy dissipation and conditions for their correct use. In: Structural engineering world congress (SEW5), proceedings on CD, Abstract Volume, p 115

Martelli A, Sannino U, Parducci A, Braga F (eds) (2008) Moderni Sistemi e Tecnologie Antisismici. Una Guida per il Progettista. In: Irsuti R (ed) Milan, 21mo Secolo

Martelli A, Clemente P, Forni M, Panza G, Salvatori A (2011) Recent development and application of seismic isolation and energy dissipation systems, in particular in Italy, conditions for their correct use and recommendations for code improvement. In: 12th World conference on 
seismic isolation, energy dissipation and active vibration control of structures, proceedings on CD, Russian Federation, Sochi, Abstract Volume, pp 9-11, 20-23 Sept 2011

Martelli A, Clemente P, Forni M (2012a) Recent worldwide application of seismic isolation and energy dissipation to steel and other materials structures and conditions for their correct use. In: STESSA 2012 - behaviour of steel structures in seismic areas, Santiago, Chile, pp 3-14, 9-11 Jan 2012

Martelli A, Forni M, Clemente P (2012b) Development and application of anti-seismic systems in Italy and worldwide and conditions for their correct use. In: EACS 2012 - 5th European conference on structural control, Proceeding on CD, Genova, Italy,Abstract Volume, p 160, 18-20 June

Martelli A, Forni M, Clemente P (2012c) Recent worldwide application of seismic isolation and energy dissipation and conditions for their correct use. In: Proceedings on electronic key of the 15th World conference on earthquake engineering (15WCEE), Lisbon, Conference programme, p 52, 24-28 Sept 2012

Martelli A, Forni M, Panza G (2013a) Features, recent application and conditions for the correct use of seismic isolation systems. In: Syngellakis S (ed) Seismic control systems: design and performance assessment. Wit Press, Southampton, pp 1-16

Martelli A, Clemente P, De Stefano A, Forni M, Salvatori A (2013b) Development and application of seismic isolation, energy dissipation and other vibration control techniques in Italy for the protection of civil structures, cultural heritage and industrial plants. Key-note lecture. In: Seismic isolation, energy dissipation and active vibration control of structures; Proceeding on electronic key of the ASSISi 13th World conference (13WCSI) \& JSSI 20th Anniversary international symposium, JSSI, Sendai, Japan/Tokyo, 24-26 Sept 2013

Martelli A, Clemente P, De Stefano A (2013c) On the benefits of a wide use of anti-seismic systems for the seismic protection of schools and high risk chemical plants. Invited lecture. In: Seismic isolation, energy dissipation and active vibration control of structures; Proceeding on electronic key of the ASSISi 13th World conference (13WCSI) \& JSSI 20th Anniversary international symposium, JSSI, Sendai, Japan/Tokyo, 24-26 Sept 2013

Martelli A, De Stefano A, Vizzaccaro A (2013d) Scuole sicure: diritto e dovere della società civile. In: Villaggio Globale, http://vglobale.it, Naples, Italy 61 (in Italian)

Mazzolani FM, Herrera R (eds) (2012) STESSA 2012 - behaviour of steel structures in seismic areas; proceeding of the STESSA 2012 conference, CRC Press - Taylor and Francis Group, Santiago, Chile/Leiden, 9-11 Jan 2012

Panza G, Irikura K, Kouteva M, Peresan A, Wang Z, Saragoni R (eds) (2011) Advanced seismic hazard assessment. In: Pageoph Topical Volume, ISBN 978-3-0348-0039-6 \& ISBN: 978-30348-0091-4

Salvatori A (2013) Il sistema CAM nel recupero dei centri storici. Esempi applicativi. In: Come ricostruire in sicurezza sismica i centri storici, In: GLIS/ANCE/ENEA conference, L'Aquila, Italy, pdf versions of the ppt presentations, www.assisi-antiseismicsystems.org (in Italian), 13 Dec 2013

Sannino U, Sandi H, Martelli A, Vlad I (eds) (2009) Modern systems for mitigation of seismic action - proceedings of the symposium held at Bucharest, Romania, on 31 Oct 2008, AGIR Publishing House, Bucharest, ISBN 978-973-720-223-9

Zhou FL, Tan P, Heisa WLH, Xian XL (2013) Lu Shan earthquake M7.0 on 2013.4.20 and recent development on seismic isolation, energy dissipation \& structural control in China. Key-note lecture. In: Seismic isolation, energy dissipation and active vibration control of structures; Proceeding on electronic key of the ASSISi 13th world conference (13WCSI) \& JSSI 20th anniversary international symposium, JSSI, Sendai, Japan/Tokyo, 24-26 Sept 2013 